\title{
Article \\ Alpha-Helical Protein KfrC Acts as a Switch between the Lateral and Vertical Modes of Dissemination of Broad-Host-Range RA3 Plasmid from IncU (IncP-6) Incompatibility Group
}

\author{
Monika Mitura ${ }^{1}$ (), Ewa Lewicka ${ }^{1}$, Jolanta Godziszewska ${ }^{1}$, Malgorzata Adamczyk ${ }^{2}{ }^{\circledR}$ and \\ Grazyna Jagura-Burdzy ${ }^{1, *(\mathbb{D})}$ \\ 1 Laboratory of DNA Segregation and Cell Cycle of Proteobacteria, Institute of Biochemistry and Biophysics, \\ Polish Academy of Sciences, 02-106 Warsaw, Poland; mmitura@ibb.waw.pl (M.M.); \\ e.sloniewska@ibb.waw.pl (E.L.); godziszewskaj@gmail.com (J.G.) \\ 2 Faculty of Chemistry, Chair of Drug and Cosmetics Biotechnology, Warsaw University of Technology, \\ 00-664 Warsaw, Poland; madamczyk@ch.pw.edu.pl \\ * Correspondence: gjburdzy@ibb.waw.pl; Tel.: +48-22-592-1212
}

\section{check for}

updates

Citation: Mitura, M.; Lewicka, E.; Godziszewska, J.; Adamczyk, M.; Jagura-Burdzy, G. Alpha-Helical Protein KfrC Acts as a Switch between the Lateral and Vertical Modes of Dissemination of Broad-Host-Range RA3 Plasmid from IncU (IncP-6) Incompatibility Group. Int. J. Mol. Sci. 2021, 22, 4880. https://doi.org/10.3390/ijms22094880

Academic Editor: Baltasar Mayo

Received: 31 March 2021

Accepted: 3 May 2021

Published: 5 May 2021

Publisher's Note: MDPI stays neutral with regard to jurisdictional claims in published maps and institutional affiliations.

Copyright: (c) 2021 by the authors. Licensee MDPI, Basel, Switzerland. This article is an open access article distributed under the terms and conditions of the Creative Commons Attribution (CC BY) license (https:/ / creativecommons.org/licenses/by/ $4.0 /)$.

\begin{abstract}
KfrC proteins are encoded by the conjugative broad-host-range plasmids that also encode alpha-helical filament-forming KfrA proteins as exemplified by the RA3 plasmid from the IncU incompatibility group. The RA3 variants impaired in $k f r A, k f r C$, or both affected the host's growth and demonstrated the altered stability in a species-specific manner. In a search for partners of the alpha-helical KfrC protein, the host's membrane proteins and four RA3-encoded proteins were found, including the filamentous KfrA protein, segrosome protein KorB, and the T4SS proteins, the coupling protein VirD4 and ATPase VirB4. The C-terminal, 112-residue dimerization domain of KfrC was involved in the interactions with KorB, the master player of the active partition, and VirD4, a key component of the conjugative transfer process. In Pseudomonas putida, but not in Escherichia coli, the lack of KfrC decreased the stability but improved the transfer ability. We showed that KfrC and KfrA were involved in the plasmid maintenance and conjugative transfer and that KfrC may play a species-dependent role of a switch between vertical and horizontal modes of RA3 spreading.
\end{abstract}

Keywords: alpha-helical KfrC protein; broad-host-range RA3 plasmid; IncU (IncP-6) group; active partition; conjugative transfer

\section{Introduction}

The existence of a complex filamentous network called the cytoskeleton that spatially organizes the content of a cell has long been regarded as typical for eukaryotic cells. About 30 years ago, the bacterial cell division tubulin-like protein FtsZ, which was able to selfassemble into fibers, was discovered. It initiated the identification of various prokaryotic cytoskeletal proteins that are homologous to all three major types of filament-forming proteins comprising the eukaryotic cytoskeleton: actin (e.g., MreB, FtsA, MamK, and Alp), tubulin (e.g., FtsZ, TubZ, and PhuZ) and intermediate filament IF (e.g., crescentin) [1-3]. These proteins have been shown to fulfill pivotal cellular functions (reviewed in [4,5]) such as cell wall synthesis, maintenance of a cell's shape, cell division, as well as DNA segregation and organization of intracellular components [6]. Besides the canonical cytoskeletal proteins, a variety of filament-forming proteins found in bacteria have no eukaryotic homologs, highlighting the complexity of the bacterial cytoskeleton. Among them are the Walker A Cytoskeletal ATPases (WACAs), a widely distributed subfamily of the Ploop NTPases that form ATP-dependent filaments involved in DNA segregation and cell division [7], and bactofilins performing a range of different cytoskeletal tasks [7,8]. Furthermore, there is a growing group of coiled-coil-rich proteins (CCRPs) that are putatively able to polymerize into filamentous structures in a nucleotide-independent manner mediated by 
the coiled-coils but lacking in typical features of eukaryotic IF proteins. They are considered as a component of the bacterial cytoskeleton or to play an auxiliary function, but, so far, they have not been investigated as extensively as the aforementioned proteins $[5,9,10]$.

Prokaryotic cytoskeletal proteins have been found encoded not only chromosomally but also by phages $[11,12]$ and the low-copy-number plasmids from different incompatibility groups in which they convey the function of plasmid DNA segregation [7]. Noticeably, the conjugative plasmids of the IncP, IncU, IncW, and PromA groups that are able to replicate, be stably maintained, and efficiently disseminate in a broad range of hosts encode the alpha-helical, coiled-coil-containing, DNA-binding proteins, designated KfrAs [13-20]. It has been recently shown that the presence of KfrAs is widely spread in various species [18]. At least for the IncP and IncU homologues, it was shown that filament-forming KfrAs play an accessory function in the proper plasmid segregation [13-20]. In the same two groups of the BHR conjugative plasmids, KfrAs are accompanied by presumably alpha-helical proteins, designated KfrCs, with which KfrAs interact $[13,18,21]$. The questions how they act and what exactly their auxiliary role is in plasmid segregation remain unanswered.

The object of our research, conjugative broad-host-range RA3 plasmid, an archetype of the IncU incompatibility group (designated IncP-6 in Pseudomonas spp), is a unit-copy replicon of $45.9 \mathrm{~kb}$ (GeneBank Accession no. DQ401103) that is able to transfer and be maintained in Alpha-, Beta- and Gammaproteobacteria [22]. The RA3 backbone genome contains the clusters of functionally related genes, designated the replication, the stability, and the conjugation modules.

The backbone functions are regulated by several autoregulators [23,24] and two global regulators, KorB and KorC, coordinating all plasmid functions (Figure 1A) [17,25]. An additional regulatory mechanism detected during analysis of the RA3 stability module expression is based on the transcriptional organization of this module and adjusts the particular gene transcript dosage to the various hosts (Figure 1B) [26]. Two important cisacting sites, parS, the centromere-like site of the active partition system, and oriT, the origin of the conjugative transfer, are adjacent in the RA3 genome (Figure 1C) and may impose a steric hindrance between segrosome [24] and relaxosome complexes [27]. Within the stabilization module, upstream of the type Ia active partition system encoding KorB of the ParB family and IncC, the Walker-type ATPase of the ParA family, there are two structural genes for alpha-helical proteins KfrA and $\mathrm{KfrC}[22,28]$. It has been shown recently that KfrA acts as a transcriptional autoregulator and is able to form long filamentous structures in the presence of plasmids carrying its cognate binding site $[18,29]$. Moreover, it forms a complex with $\mathrm{KfrC}$ and with both active partitioning proteins, KorB and IncC [18]. The highly unstable test plasmid that was stabilized by the presence of the RA3 stability module displayed the increased segregation rate in some hosts when deprived of the $k f r A$ operon [26,29] and/or $k f r C ~[18]$. To better understand the functions the Kfr proteins play in the RA3 plasmid biology, the present study focused on the detailed analysis of the $\mathrm{KfrC}$ properties and on a wide-range search for $\mathrm{KfrC}$ partners among the plasmid RA3- and host-encoded proteins.

Using this approach, we identified the conjugative coupling protein VirD4 as the $\mathrm{KfrC}_{\mathrm{RA} 3}$ partner and mapped their interaction domains. The interplay between the conjugative transfer and the active segregation processes was demonstrated. $\mathrm{KfrC}$ plays an important species-dependent role in the switch between the horizontal and vertical spreading of RA3. 
A Replication Maintenance

Conjugative transfer

Load

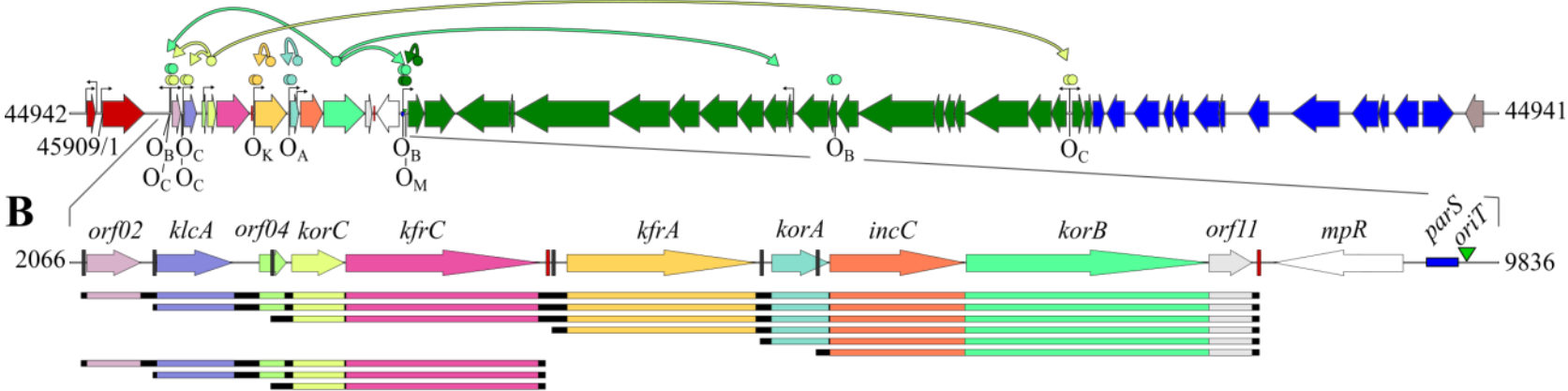

C

IR-DR1

IR-DR2

CTAGTGCCCTGCTCCGTGTATTGGATTGCACAATCTATAACCATTATGCGGCAGCCTTTTGGATTGCA $\vec{\longrightarrow}$

9548 GATCACGGGACGAGGCACATAACCTAACGT GTTAGATATTGGTAATACGCCGTCGGAAAACCTAACGTGTTAGGTTTCAATCCCCTTCGGCTGCTCGGT poors

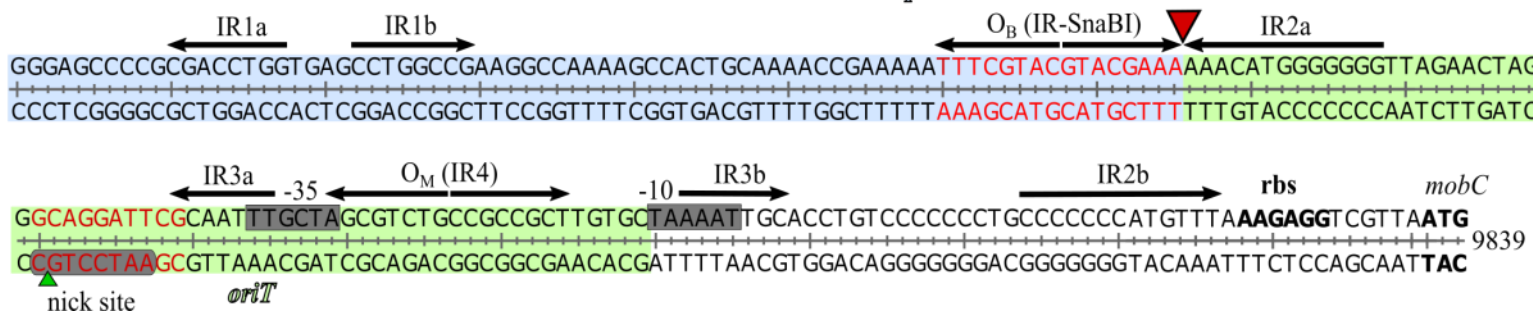

Figure 1. Genetic organization of RA3 plasmid from IncU incompatibility group (GenBank: DQ401103.1). (A) Linear map of RA3 plasmid. The replication module is in red, stability module is multicolored (close-up in Panel B), the conjugative module in green, and integron in blue. ORFs are represented by thick arrows that point out the direction of transcription. Thin black arrows in the backbone fragment indicate the transcription start sites (TSS). The colored arrows connecting the regulatory genes with the action sites of their products demonstrate the regulatory circuits $\left(\mathrm{O}_{\mathrm{A}}\right.$-operator for Kor $\mathrm{A}$, $\mathrm{O}_{\mathrm{B}}$ for $\mathrm{KorB}, \mathrm{O}_{\mathrm{C}}$ for $\mathrm{KorC}, \mathrm{O}_{\mathrm{K}}$ for $\mathrm{KfrA}$, and $\mathrm{O}_{\mathrm{M}}$ for MobC). (B) RA3 maintenance module with the identified variants of the transcripts for particular genes [26]. Black boxes indicate promoters and red boxes depict Rho-independent transcriptional terminator sites. A cis-acting site in partition, parS, marked as a blue rectangle, is located in the vicinity of the origin of conjugative transfer oriT, marked as a green triangle. (C) DNA sequence of RA3 parS/oriT region located at the border of the maintenance and conjugative transfer modules. Direct motifs (DR) and arms of inverted repeats (IR) are depicted by arrows. The centromere-like parS region encompassing the binding site $\mathrm{O}_{\mathrm{B}}$ (IR-SnaBI) for partitioning protein KorB preceded by IR-DRs is highlighted in blue [24]. The oriT region located between $\mathrm{O}_{\mathrm{B}}$ and including $\mathrm{O}_{\mathrm{M}}$ (operator for MobC) overlaps mobC $p$ (grey boxes) and is highlighted in green. The conserved nick motif is circled in grey with a green triangle indicating a relaxase nicking site. The ribosome binding site (rbs) and start codon for MobC are in bold. The parS and oriT sequences deleted in RA3 mutants are denoted in red whereas the site of DNA insertion to separate parS and oriT motifs is pointed out by a red triangle.

\section{Results}

\subsection{Role of KfrA and KfrC in the Stable Maintenance of RA3 Derivatives in Various Hosts}

Previous studies on $\mathrm{KfrA}_{\mathrm{RA} 3}$ and $\mathrm{KfrC}_{\mathrm{RA} 3}$ roles in the stability of the low-copynumber plasmid were conducted with the use of the test vector pESB36 based on the RK2 minireplicon [26]. The very unstable pESB36 was efficiently stabilized by the presence of the orf02-orf11 RA3 stability module in the E. coli strain as well as in the other tested hosts but to a various extent. Deletion of either kfrs from the module or even substitution of WT $k f r A$ by the mutated allele $k f r A_{L 43 A}$, producing KfrA unable to bind specifically to DNA, led to the high plasmid instability in E. coli [18] and in other hosts. It seemed important to follow the effects of kfrs deletions on maintaining of the whole RA3 plasmid, i.e., in the presence of the immanent replication system and the conjugative transfer module. 
Deletion mutants of RA3, RA3 $k k f r A$, RA $3 \Delta k f r C$, and RA3 $\Delta(k f r C-k f r A)$, were constructed by replacing particular ORF(s) with the $\mathrm{Km}^{\mathrm{r}}$ cassette [30]. For each RA3 deletion derivative, the growth rate and the stability functions were determined in the various hosts. The presence of WT RA3 decreased the growth rate by $25 \%$ and clearly increased the number of filamentous cells $(>4 \mu \mathrm{m})$ from $19 \%$ in $\mathrm{DH} 5 \alpha$ to $37 \%$ in $\mathrm{DH} 5 \alpha(\mathrm{RA} 3)$ given the average cell length elevated by $31 \%$ (Figure 2A,B). Deletion of the $k f r C$ gene potentiated the effect of filamentation shifting the number of cells longer than $4 \mu \mathrm{m}$ up to $70 \%$ and the average cell length about $75 \%$ in comparison to DH5 $\alpha$ (from $3.23 \mu \mathrm{m}$ to $5.66 \mu \mathrm{m}$ ). Hence, the presence of RA3 deprived of $k f r C$ disturbs cell division, leading to the further filamentation and the longer generation time (Figure 2B). Notably, monitoring the plasmid retention during approximately 60 generations of growth without a selection demonstrated loss of neither of the four plasmids in the E. coli host (inset in Figure 2A).

WT RA3 and three deletion mutants were introduced via conjugation into two other strains of Gammaproteobacteria, Pseudomonas putida and Aeromonas veronii, and the representative strains of Alpha- and Betaproteobacteria, Paracoccus aminovorans and Cupriavidus necator, respectively. The growth of $P$. putida KT2442, similarly to DH5 $\alpha$, was retarded in the presence of RA3 plasmid (Figure 2C). While removal of KfrA increased generation time from $41 \mathrm{~min}$ to $44 \mathrm{~min}$, the presence of RA $3 \Delta k f r C$ and $\mathrm{RA} 3 \Delta(k f r C-k f r A)$ extended generation time to $49 \mathrm{~min}$. Here, the results were in-line with the decreased retention of RA3 derivatives. RA3 $\Delta k f r A$ segregated slower than the other two variants, RA3 $k k f r C$ and RA $3 \Delta(k f r C-k f r A)$, which were lost from the population after only 20 generations of growth without selection (inset in Figure 2C).

In $A$. veronii, only the presence of RA3 $\Delta k f r A$ increased the generation time by $5 \%$ despite that all three deletion derivatives were less stable than WT RA3. Among them, RA3 $\Delta k f r A$ segregated quicker than the two other mutants did (Figure 2D).

No clear difference in the growth rate and stability was observed between transformants carrying WT RA3 and its three derivatives in P. aminovorans of Alphaproteobacteria (Figure 2E).

In C. necator of Betaproteobacteria, seemingly no effect on growth rate was observed in transconjugants of all three derivatives in comparison to the WT RA3 transconjugant (Figure 2F). Stability experiments, however, demonstrated increased retention of the RA3 variants with deletions in the $k f r$ genes in comparison to WT RA3 (inset in Figure 2F), suggesting the negative interference of Kfrs in the stable maintenance of RA3 in this host. 

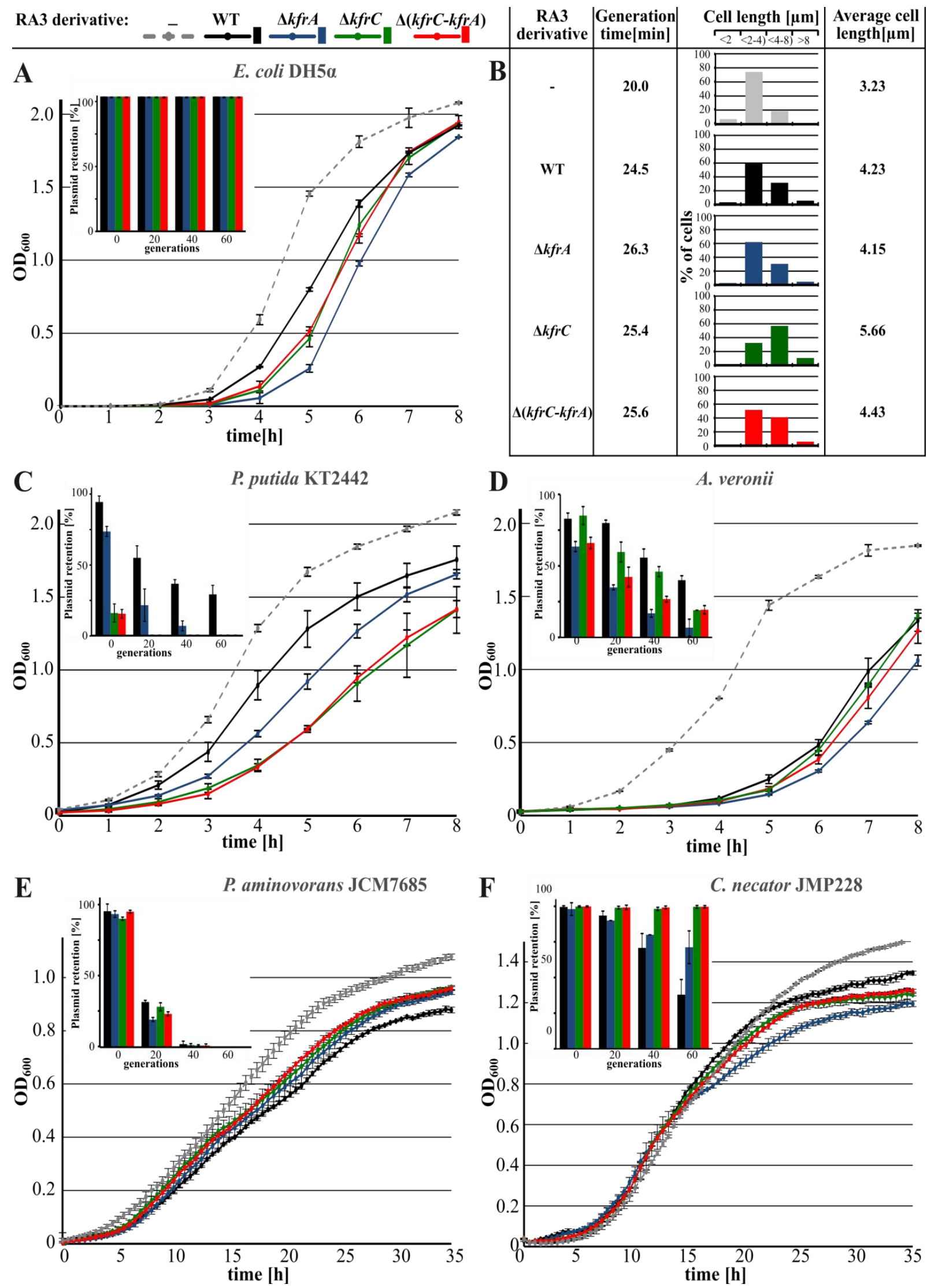

Figure 2. RA3 deletion variants in various hosts. (A) Growth of E. coli DH5 $\alpha$ strain transformed with various RA3 derivatives. The inset demonstrates the results of the stability experiment carried on in triplicates. Plasmid retention was 
analyzed during 60 generations of growth without selection, estimated every 20 generations as the \% of antibiotic-resistant colonies. (B) Generation time of the DH5 $\alpha$ transformants was calculated based on the colony forming units (c.f.u.) at different time points. Microscopic observations of DAPI-stained cells were the basis for the cell size profiling and calculation of the average cell length. (C) Growth and plasmid stability (inset) of the RA3 transconjugants of P. putida KT2442 strain. (D) Growth and plasmid stability (inset) of the RA3 transconjugants of A. veronii strain. (E) Growth and plasmid stability of the RA3 transconjugants of P. aminovorans JCM7685 strain. (F) Growth and plasmid stability of the RA3 transconjugants of C. necator JMP228 strain. Transformants and transconjugants were grown in L broth at the appropriate temperature and streptomycin concentration. Broken lines represent growth curves of the plasmid-less hosts grown without antibiotic. The presented results are representative of three experiments and show average from three biological repeats (cultures grown in parallel) with standard deviation.

\section{2. $\mathrm{Kfr}_{\mathrm{RA3}}$ Structure}

KfrC of RA3 (355 amino acids) is homologous (68\% identity) in the first 240 residues to the N-terminal part of $\mathrm{KfrC}(448$ amino acids) from $\mathrm{RK} 2(\operatorname{IncP} \alpha)$. Interestingly, this $\mathrm{N}$-terminus of $\mathrm{KfrC}_{\mathrm{RK} 2}$ is deleted in the representatives of IncP $\beta$, e.g., R751 (Figure 3A). Since the remaining part of $\mathrm{KfrC}_{\mathrm{RA} 3}$ (115 amino acids) has no homologs in the database, the $k f r C_{\mathrm{RA3}}$ gene was split accordingly into two fragments (encoding 1-249 and 244-355 amino acids) to find out their potential functions. The predicted model of $\mathrm{KfrC}_{\mathrm{RA} 3}$ by I-TASSER is shown in Figure 3B, with two domains differently colored. The N-terminal domain not only contains conserved 5-phosphoribosyl-1-pyrophosphate (PRPP) binding motif (V56-H173) (Figure 3A) but also has the characteristic fold of phosphoribosyltransferase (PRT)-type I domain (Pfam: PF00156).

The model of $\mathrm{KfrC}_{\mathrm{RA} 3}$ by I-TASSER predicted the high content of alpha-helices (Figure 3B). To verify it, the kfrC gene was cloned into pET28 derivative (pESB15.90) and the KfrC-His 6 protein was purified by affinity chromatography. It was shown that C-terminally $\mathrm{His}_{6}$-tagged $\mathrm{KfrC}$ (pOMB9.29), when over-produced in E. coli, retained the properties of the intact $\mathrm{KfrC}$ (see the next section).

The purified $\mathrm{KfrC}$ demonstrated the dominance of the monomeric form $(40 \mathrm{kDa})$ in solution as shown via SEC-MALS analysis (Figure $3 \mathrm{C}$ ). The $\mathrm{KfrC}$ potential to dimerize was tested during in vitro experiments by the use of the cross-linking agent glutaraldehyde (GA). After cross-linking the extracts of induced BL21(DE3) pESB15.90 (kfrC-his $_{6}$ ) or pOMB8.28 $\left(\mathrm{kfr}_{244-355}-\mathrm{his}_{6}\right)$, transformants were separated by PAGE and KfrC was visualized by Western blotting with anti-His tag antibodies. The extract from BL21(DE3) pKAB28.7 (empty vector) was also treated with $0.1 \%$ glutaraldehyde and used as a control (Figure 3D,E). The ability of KfrC to form dimers and the higher-order complexes was demonstrated. A similar spectrum of complexes was observed after cross-linking of $\mathrm{KfrC}_{244-355}$, pointing out this part of $\mathrm{KfrC}$ as the dimerization domain.

The secondary structure of KfrC was analyzed using the circular dichroism method (Figure 3F,G). It confirmed the alpha-helical structure of $\mathrm{KfrC}$ in the range of temperatures between $25{ }^{\circ} \mathrm{C}$ and $42{ }^{\circ} \mathrm{C}$. Addition of TFE (2,2,2-trifluoroethanol) [31] promoted the stability of the molecules, increasing the estimated alpha-helix content from $43 \%$ to $62 \%$. 
A

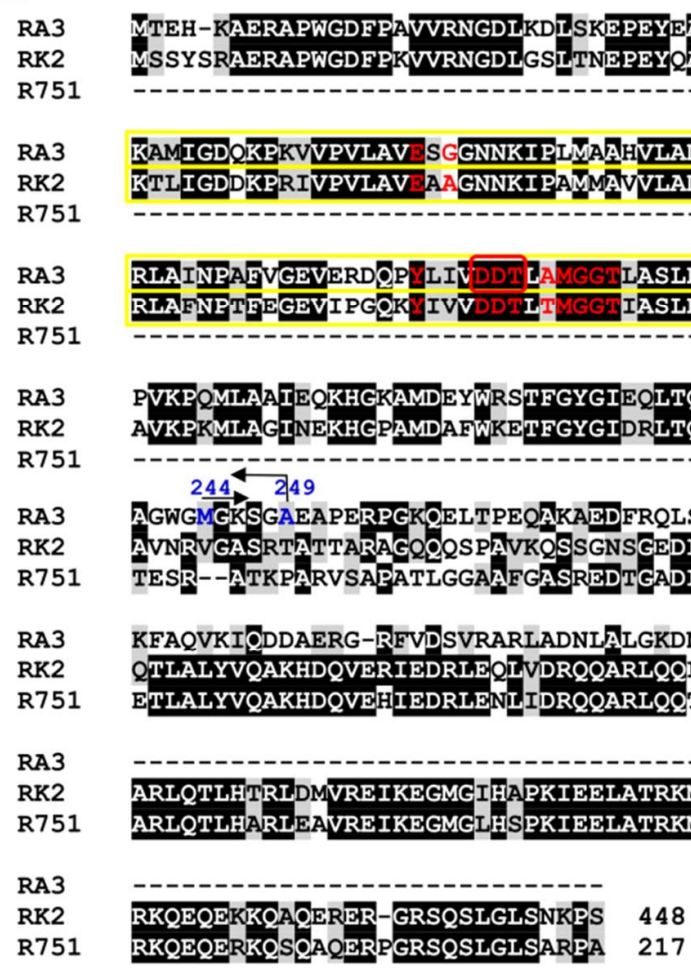

R751 RKQEQERKQSQAQERPGRSQSLGLSARPA 217
C

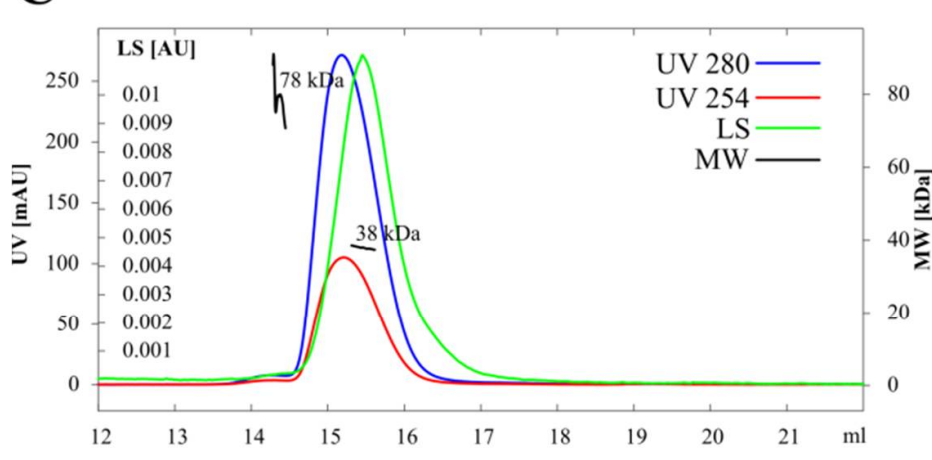

$\mathbf{F}$

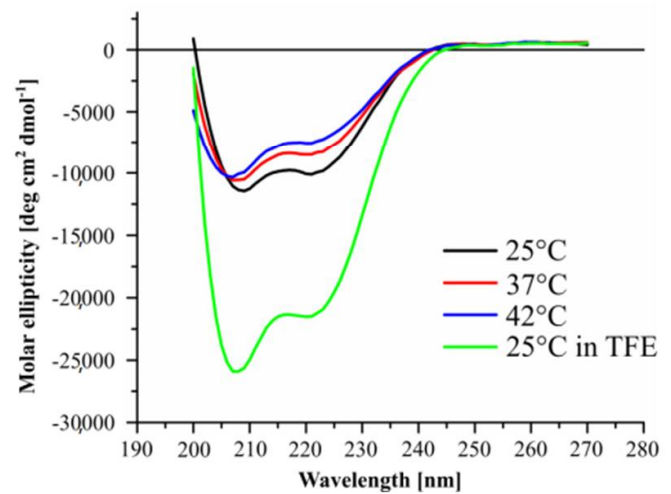

B

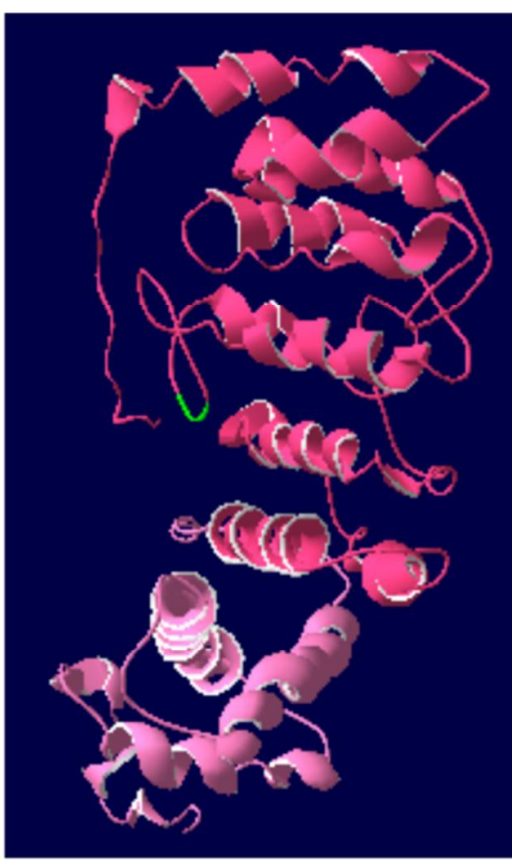

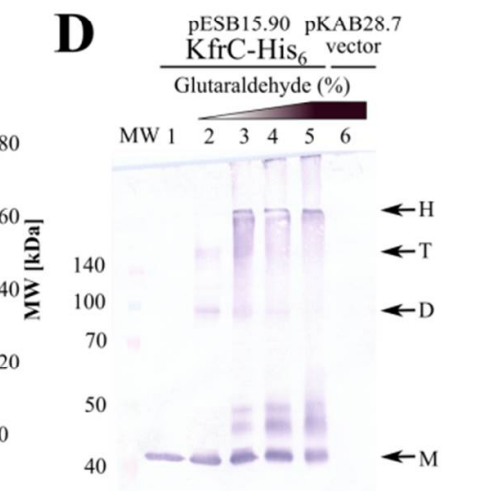

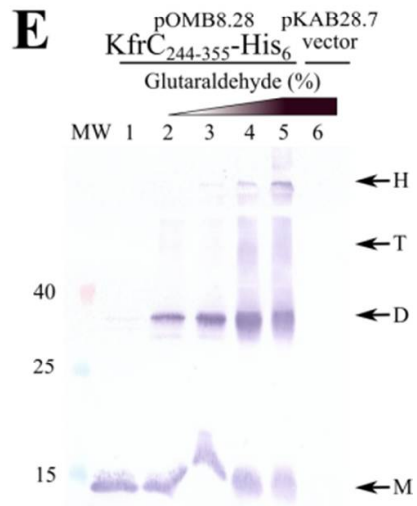

G

without TFE

in TFE
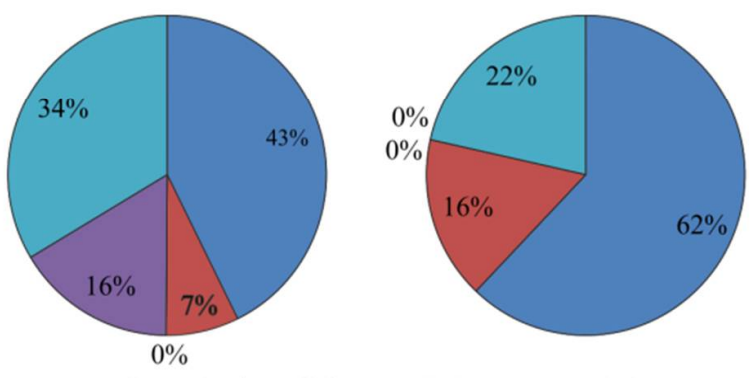

$\square$ Helix $\square$ Antiparallel $\square$ Parallel $\square$ Turn $\square$ Others

Figure 3. $\mathrm{KfrC}_{\mathrm{RA} 3}$ structure analysis. (A) Alignment of the closest homologs of $\mathrm{KfrC}_{\mathrm{RA} 3}$ (IncU) [ABD64834.1], $\mathrm{KfrC} \mathrm{RK}_{\mathrm{R}}$ (IncP-1 $\alpha$ ) [CAJ85732.1], and $\mathrm{KfrC}_{\mathrm{R} 751}$ (IncP-1 $\beta$ ) [AAC64416.1]. Identical residues are shadowed in black, similar in grey. Phosphoribosyltransferase (PRT)-type I domain (Pfam: PF00156) is encircled yellow, putative active sites indicated with red font. The $\mathrm{KfrC}_{\mathrm{RA} 3}$ residues substituted by alanine are encircled red. Residues in blue indicate the ends of the $\mathrm{KfrC} \mathrm{R}_{\mathrm{R} 3}$ truncations. (B) Structural $\mathrm{KfrC}_{\mathrm{RA} 3}$ model predicted by I-TASSER [32]. N-terminal region is highlighted in dark pink, 
C-terminal region in light pink. The $\mathrm{KfrC}_{\mathrm{RA} 3}$ residues substituted by alanine are indicated in green. (C) SEC-MALS analysis. The column was equilibrated with $50 \mathrm{mM} \mathrm{NaPi}$ buffer ( $\mathrm{pH} 7.5$ ), $0.15 \mathrm{M} \mathrm{NaCl}$ and KfrC-His 6 tagged protein was dissolved in the same buffer at the final concentration of $1 \mathrm{mg} \mathrm{mL}^{-1}$. The chromatograms display curves for the light scattering (LS) and UV readings at $280 \mathrm{~nm}$ and $254 \mathrm{~nm}$, in green, blue, and red, respectively. The scale for the LS detector is shown on the left-hand axis. The black lines (MW) indicate the calculated mass of the eluted protein (scale on the left-hand axis). The predicted molecular mass of KfrC-His ${ }_{6}$ monomer is $40.11 \mathrm{kDa}$. (D,E) In vivo crosslinking of the tagged $\mathrm{KfrC}^{-\mathrm{His}_{6}}$ and $\mathrm{KfrC}_{244-355}$-His $_{6}$ proteins. The cell extracts of BL21(DE3) transformants containing overproduced proteins were used in the crosslinking reactions with different concentrations of glutaraldehyde. The predicted molecular mass of $\mathrm{KfrC}_{244-355}-\mathrm{His}_{6}$ monomer is $14.48 \mathrm{kDa}$. Complexes were separated by SDS-PAGE and analyzed by Western blotting using anti-His 6 antibodies. Arrowheads indicate detected signals for monomers (M), dimers (D), tetramers (T), as well as the higher molecular aggregates $(\mathrm{H})$. Lane $\mathrm{MW}$-molecular weight marker [kDa], lanes 1-5-increasing concentrations of glutaraldehyde: $\%, 0.001 \%, 0.002 \%, 0.005 \%$, and $0.01 \%$, respectively. The extract of BL21(DE3) strain containing pKAB28.7 $(\mathrm{T} 7 \mathrm{p}$-his 6 ) was used as a control with $0.01 \%$ glutaraldehyde (lane 6). (F) Far-UV circular dichroism spectra. The CD spectra were measured at various temperatures, and with the addition of TFE at a temperature of $25^{\circ} \mathrm{C}$. (G) The secondary structures estimated with the BestSel program [33] for $\mathrm{KfrC}_{\mathrm{RA} 3}$ with or without the addition of TFE at a temperature of $25^{\circ} \mathrm{C}$ are presented.

\subsection{Inhibition of Hosts' Growth by the Abundance of Kfr Proteins}

The WT kfrC gene and the $3^{\prime} k f r C$ fragment encoding $\mathrm{KfrC}_{244-355}$ were cloned into the high-copy-number expression vector pGBT30 and overproduced in the E. coli DH5 $\alpha$ strain. Overexpression of the intact $k f r C$ from pESB5.88 caused significant retardation of the host growth (Figure 4A) as overproduction of $\mathrm{KfrC}^{-\mathrm{His}_{6}}$ did (pOMB9.29). The abundance of the C-terminal fragment of $\mathrm{KfrC}_{\mathrm{RA} 3}$ (pOMB9.18) did not affect the bacteria growth whereas attempts to clone the $k f r C_{1-249}$ under tacp into pGBT30 led to the various plasmid DNA rearrangements. Since the $\mathrm{N}$-terminal part of $\mathrm{KfrC}_{\mathrm{RA} 3}$ was predicted to encode a putative phosphoribosyltransferase, it was decided to modify the postulated enzymatic center (DDT motif at positions 141-143, Figure 3A) by the triple alanine substitutions. The clone was stable and the variant designated $\mathrm{KfrC}^{*}$ when overproduced (pOMB9.31) did not cause growth retardation of the E. coli DH5 $\alpha$ transformant (Figure $4 \mathrm{~A}$ ). This suggests that the toxicity of $\mathrm{KfrC}$ might be related to its putative enzymatic activity.

To analyze the KfrC overproduction effect in other RA3 hosts, the $k f r C$ was recloned under control of tacp into mobilizable pESB11, the modified BHR vector to obtain pOMB12.15. The excess of KfrC on the host growth was tested in P. putida, another representative of Gammaproteobacteria, Agrobacterium tumefaciens, the representative of Alphaproteobacteria, and C. necator of Betaproteobacteria. The $\mathrm{KfrC}$ "toxicity" was clearly host-dependent. Strong growth inhibition was observed in A. tumefaciens (Figure 4C), the weaker inhibition in P. putida (Figure 4B), and no effect of KfrC overproduction was observed in C. necator (Figure 4D).

Microscopic observations of various hosts cells carrying pESB11 (vector) or pOMB12.15 $($ tacp-kfrC), grown in the presence of $0.5 \mathrm{mM}$ IPTG, revealed strong condensation of the nucleoids in the presence of KfrC excess in P. putida and E. coli. Weaker condensation effects were observed in A. tumefaciens and C. necator (Figure 4E). The species-characteristic reactions on the excess of $\mathrm{KfrC}$, e.g., growth retardation, nucleoids condensations, suggested variability of $\mathrm{KfrC}$ targets in these hosts. Since KfrC forms a complex with the KfrA [18], the effects of KfrA overproduction were also analyzed after mobilization of pESB11.58 $(t a c p-k f r A)$ to the various strains. The KfrA excess affected growth of all tested hosts much stronger than the excess of KfrC did (Figure 4A-D). 

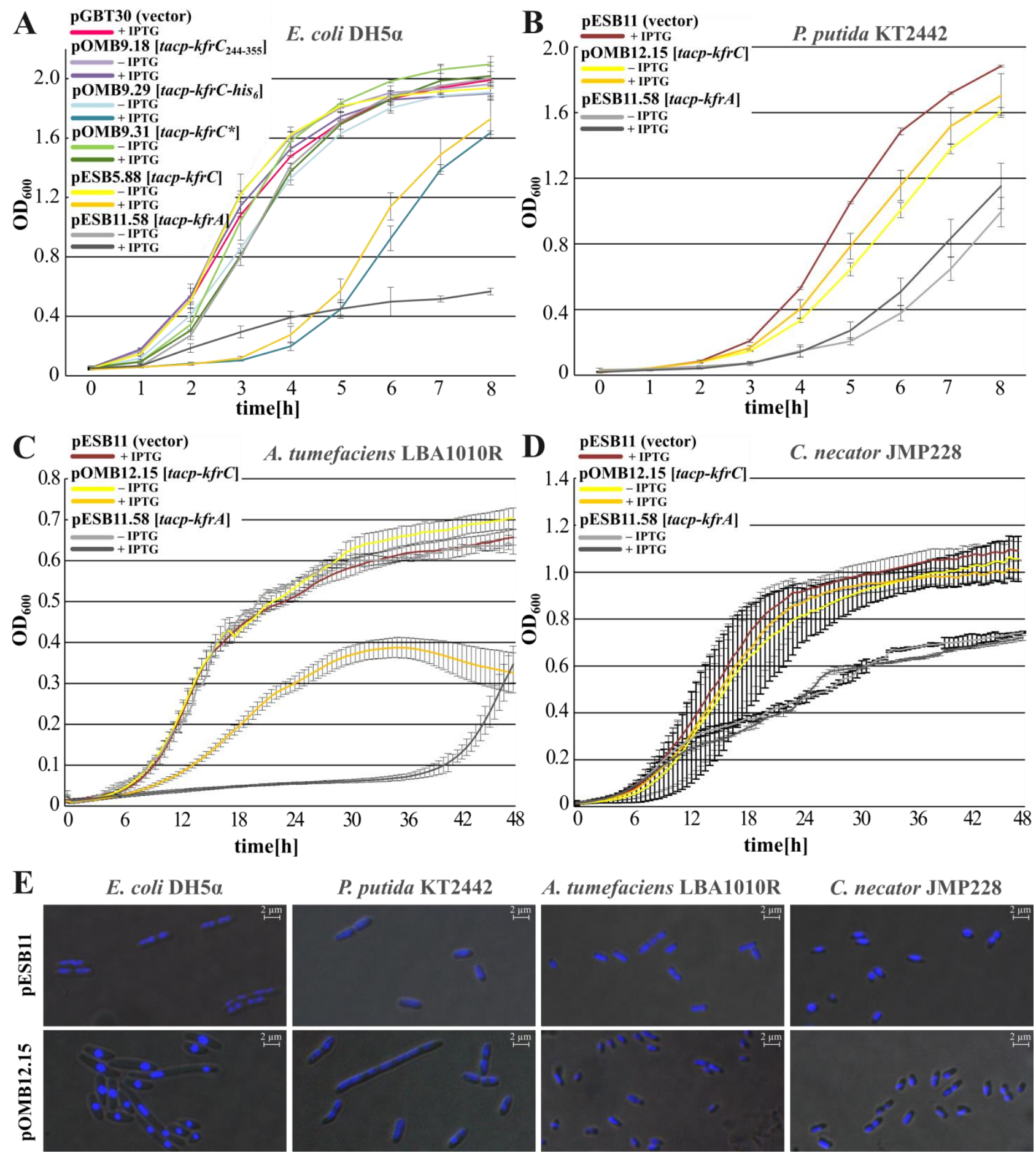

A. tumefaciens LBA1010R
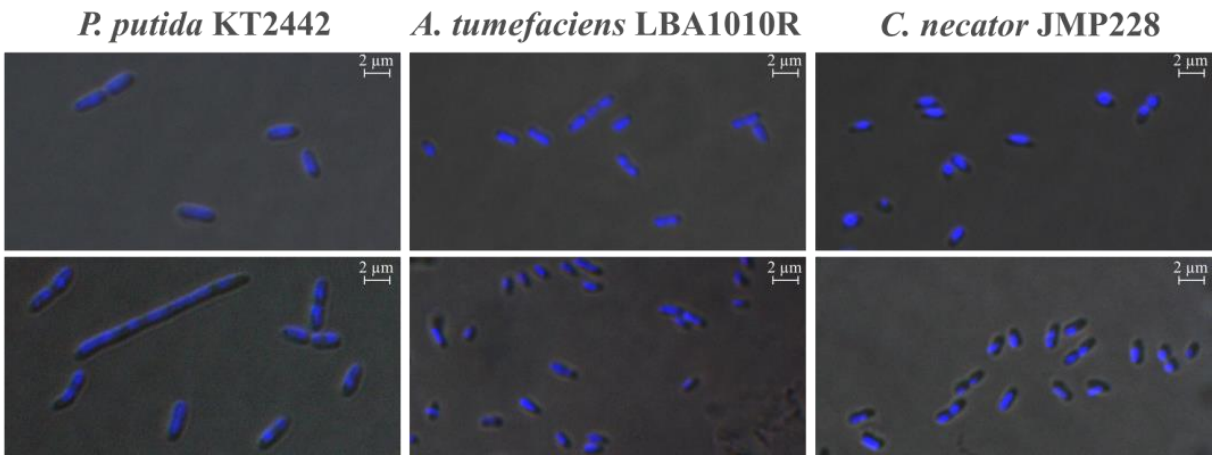

Figure 4. Overproduction of Kfr proteins. Transformants and transconjugants were grown in the selective L broth with and without $0.5 \mathrm{mM}$ IPTG at the appropriate temperature. The presented results are representative of three experiments and show the average from three biological repeats (cultures grown in parallel) with standard deviation. (A) Effects of KfrA and $\mathrm{KfrC}$ variants abundance in E. coli DH5 $\alpha$ strain. (B) Effects of KfrA and KfrC abundance in P. putida KT2442, (C) in A. tumefaciens LBA1010R, and (D) in C. necator JMP228. (E) Microscopic observations of DAPI-stained transconjugants cells carrying either an empty vector pESB11 or pOMB12.15 overproducing $\mathrm{KfrC}$. Images were intensified when required. 


\subsection{Mapping of the KfrC Domain of Self-Interactions and Interactions with KfrA and KorB}

Previous BACTH analysis [18] showed that $\mathrm{KfrC}$ and KfrA strongly interacted with each other. The ability to form a complex between these two alpha-helical proteins was also confirmed by coimmunoprecipitation experiments. The domain of interactions between $\mathrm{KfrA}$ and $\mathrm{KfrC}$ was mapped to the long alpha-helical tail (KfrA $\left.{ }_{54-355}\right)$ with the fragment KfrA $\mathrm{A}_{5-177}$ exhibiting much stronger association with $\mathrm{KfrC}$ than $\mathrm{KfrA}_{178-355}$ [18]. In this work, mapping of the KfrC domain of self-interactions and interactions with the previously identified partners, KfrA and KorB, was undertaken.

Two gene fragments $\left(k f r C_{1-249}, k f r C_{244-355}\right)$ and the intact $k f r C$ were cloned into the four vectors of BACTH [34] system facilitating translational fusions with the CyaA fragments from N- or C-termini. Re-constitution of the CyaA activity as a result of interactions between the hybrid proteins leads to the expression of sugar catabolic genes such as mal or lac operons. The ability to interact was tested on indicator MacConkey plates with maltose and activity of $\beta$-galactosidase was assayed in the liquid cultures of the E. coli BTH101 cyaA transformants. The $\mathrm{KfrC}$ dimerization domain was mapped to the C-terminal 112 amino acids $\mathrm{KfrC}_{244-355}$ (Figure 5A).

Splitting KfrC into two parts abolished strong interactions between $\mathrm{KfrA}$ and $\mathrm{KfrC}$ proteins, suggesting that either the intact $\mathrm{KfrC}$ was required to form a complex with $\mathrm{KfrA}$ or the genetic manipulation impaired the interaction domain in $\mathrm{KfrC}_{\mathrm{RA} 3}$ (Figure 5B).

Previously, it was demonstrated that both components of the Kfr complex had the ability to interact with the RA3 segrosome proteins and KfrA interacted strongly with KorB (ParB homolog) and weakly with IncC (ParA homolog), whereas KfrC interacted only with KorB [18]. Here, we mapped the domain of interactions with KorB to the C-terminal dimerization part of $\mathrm{KfrC}, \mathrm{KfrC}_{244-355}$ (Figure 5C).

\subsection{Search for the $\mathrm{KfrC}_{R A 3}$ Partners}

A wide genomic approach was undertaken to search for putative partner proteins encoded in the E. coli and A. veronii genomes since Aeromonas spp are the most widely spread RA3 hosts in the aquatic environments [35]. The high-quality ( $>95 \%$ inserts) genomic libraries of these two organisms (producing "prey" polypeptides) were prepared in the high-copy-number BACTH vector pUT18C [34] (Figure S1). The "bait" proteins, $\mathrm{CyaA}_{\mathrm{T} 25}-\mathrm{KfrC}$ (pOMB5.15) or KfrC-CyaA $\mathrm{A}_{25}$ (pOMB7.16.1), were produced in the BTH101 transformants. Selection of the possible interactants was conducted by plating BTH101 double transformants on the minimal medium with maltose as a carbon source, antibiotics, X-gal, and IPTG added to follow simultaneously the expression of the lac operon. Plasmid DNA isolated from the chosen "positive" clones was used to transform BTH101 with the appropriate bait plasmid using the same medium. Two-step screening allowed us to diminish the pool of the "false positives". Plasmid DNA isolated from the chosen clones was sequenced. The results of this search are presented in Table 1.

Screening of both libraries from E. coli and A. veronii identified mainly membraneassociated proteins and several enzymes engaged in the phosphometabolism. Since clones in the libraries encoded the fragments of the structural genes, it was necessary to validate the results by cloning complete ORFs into the BACTH system. The vast majority of the analyzed ORFs lost the ability to interact with $\mathrm{KfrC}$ in the plate tests, although there were a few that sustained this activity (Figure S2). Further studies are required to establish the functional connections between $\mathrm{KfrC}$ and these proteins.

Another approach was taken to identify the $\mathrm{KfrC}$ frontline partners, besides $\mathrm{KfrA}$, among proteins encoded by the RA3 plasmid (Table 2). The genomic library of RA3 was prepared in the same high-copy-number $\mathrm{PUT} 18 \mathrm{C}$ vector and screened in the same way as the bacterial genomic libraries. The identified partners were KfrC itself ( 3 clones), VirB4 ( 2 clones), and VirD4 (17 clones). Both VirB4 and VirD4 presumably have the ATPases activities and are components of the T4SS (Type IV secretion system) involved in the RA3 conjugation. During conjugation VirD4, the coupling protein (CP), is assumed to deliver the relaxosome complex of relaxase bound at oriT with the single-stranded plasmid DNA 
to a membrane-associated transferosome complex. VirB4 is a part of a transmembrane channel interacting directly with the $\mathrm{CP}$ and participating in the relaxosome secretion [36].

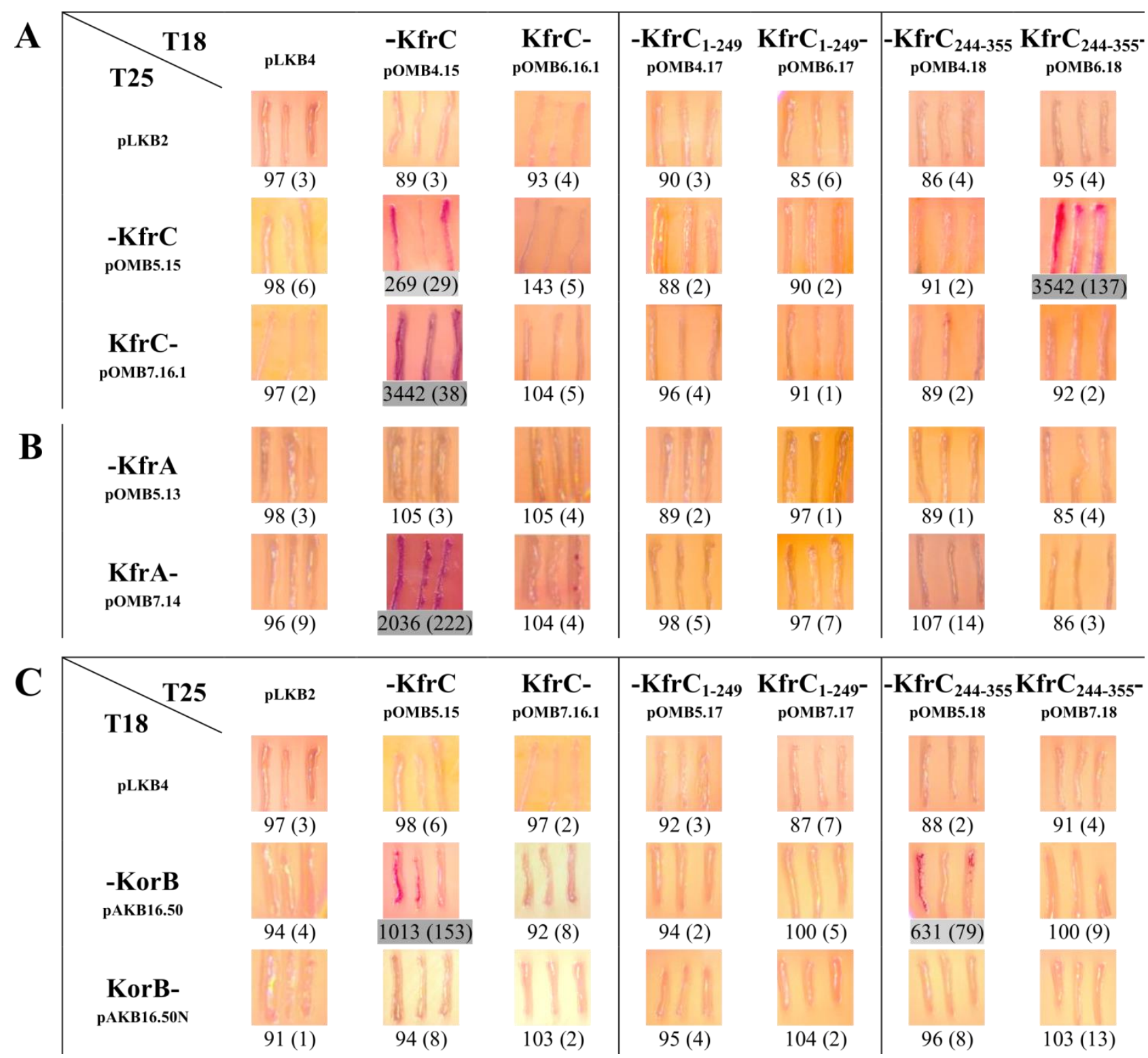

Figure 5. Mapping of the $\mathrm{KfrC}_{\mathrm{RA} 3}$ domains using the $\mathrm{BACTH}$ system. Analysis of domains involved in the homodimerization (A) and heterodimerization with $\mathrm{KfrA}(\mathbf{B})$ and $\mathrm{KorB}(\mathbf{C})$. Double transformants of E. coli BTH101 with compatible plasmids encoding CyaA fragment T18 or T25 fused to the analyzed proteins from $\mathrm{N}$ - or C-terminus were tested on indicator MacConkey plates with maltose as a carbon source and by $\beta$-galactosidase assays in the liquid cultures. Dark (purple) streaks are indicative of interactions between the two hybrid proteins. Numbers below the images represent $\beta$-galactosidase units from at least three experiments with SD in brackets. Dark grey and light grey shadings indicate strong and weak interactions, respectively. Double transformants with one empty BACTH vector versus vector encoding the full-length protein were used as the controls (the first column). 
Table 1. $\mathrm{KfrC}_{\mathrm{RA} 3}$ interactants identified in E. coli $\mathrm{DH} 5 \alpha$ and A. veronii library screenings.

\begin{tabular}{|c|c|c|c|c|c|}
\hline Library & $\begin{array}{l}\text { DNA Coordinates } \\
\quad \text { (Peptide) } *\end{array}$ & Gene & Predicted Function ** & $\begin{array}{l}\text { NCBI Accession } \\
\text { Number }\end{array}$ & $\begin{array}{c}\text { Number of } \\
\text { Clones }\end{array}$ \\
\hline \multirow{7}{*}{ E. coli DH5 $\alpha$} & $792619(209-332)$ & edd & phosphogluconate dehydratase & WP_001069467.1 & 1 \\
\hline & $1321046(266-446)$ & $f a d L$ & long-chain fatty acid transporter & WP_001295701.1 & 1 \\
\hline & $2535141(76-228)$ & yhjJ & Zn-dependent peptidase & WP_001163141.1 & 1 \\
\hline & $3019820(475-614)$ & $b t u B$ & vitamin B12 transporter & WP_000591359.1 & 1 \\
\hline & 3869607 (138-272) & $\operatorname{cof}$ & HMP-PP phosphatase & WP_001336137.1 & 1 \\
\hline & $4142310(494-648)$ & $y b g Q$ & outer membrane usher protein & WP_001350492.1 & 1 \\
\hline & $4242142(25-171)$ & ompX & outer membrane protein OmpX & WP_001295296.1 & 1 \\
\hline \multirow{5}{*}{ A. veronii } & \multicolumn{4}{|c|}{ Most similar Protein (BLASTP) } & \multirow{2}{*}{$\begin{array}{l}\text { Number of } \\
\text { Clones }\end{array}$} \\
\hline & $\begin{array}{l}\text { Protein Length } \\
\text { (Peptide) } \S\end{array}$ & & Predicted Function ** & $\begin{array}{l}\text { NCBI Accession } \\
\text { Number }\end{array}$ & \\
\hline & $354(103-354)$ & \multicolumn{2}{|c|}{ 3-deoxy-7-phosphoheptulonate synthase } & WP_113739212.1 & 1 \\
\hline & $403(184-403)$ & \multicolumn{2}{|c|}{ EAL domain-containing protein } & WP_064340963.1 & 1 \\
\hline & 385 (187-327) & \multicolumn{2}{|c|}{ acyl-CoA dehydrogenase } & WP_129504156.1 & 1 \\
\hline
\end{tabular}

*-position in the E. coli DH5 $\alpha$ genome of the first nucleotide fused to cyaA fragment; amino acid residues of the fused polypeptides are indicated in brackets; ${ }^{* *}$ - potential function based on the comparison of protein domains, § —length of the A. veronii protein most similar to the fusion protein fragment; amino acid residues of the fused polypeptides are indicated in brackets.

Table 2. Screening of the RA3 library.

\begin{tabular}{|c|c|c|c|c|}
\hline Bait & Coordinates * & Prey & Number of Clones & Cloned Fragment \\
\hline \multirow{4}{*}{ KfrC-T25 } & 16,448 & \multirow{5}{*}{ VirD4 } & 1 & 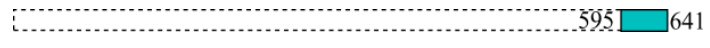 \\
\hline & 16,451 & & 8 & : \\
\hline & 16,511 & & 1 & 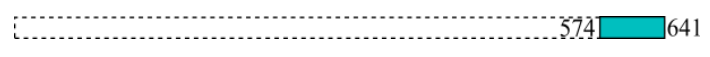 \\
\hline & 16,931 & & 3 & i \\
\hline \multirow{5}{*}{ T25-KfrC } & 17,633 & & 1 & ino........... \\
\hline & 17,501 & \multirow{2}{*}{ VirD4 } & 2 & : \\
\hline & 17,549 & & 1 & : \\
\hline & 24,447 & VirB4 & 2 & 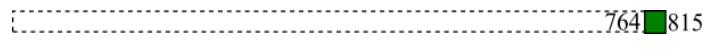 \\
\hline & 4307 & KfrC & 3 & : 355 \\
\hline
\end{tabular}

* - position of the first nucleotide of the fused fragment from the RA3 plasmid sequence.

Fourteen of the 22 "positive" clones of the RA3 library contained variable-length Ctermini of VirD4. It confirmed that the main interaction domain was inherent to the last 46 residues of VirD4 (Table 2). The three clones fished out with $\mathrm{CyaA}_{\mathrm{T} 25}-\mathrm{K}$ frC demonstrated interactions with a central part of VirD4 (244-283 residues), which suggested the possibility of two VirD4 domains of interactions with $\mathrm{KfrC}$. To verify the interactions of the full ORF, virD4 was cloned into the BACTH system and strong interactions between KfrC and VirD4 were demonstrated. It was also shown that the C-terminal part of $\mathrm{KfrC}_{\mathrm{RA} 3}$ is engaged in the interactions with VirD4 (Figure 6A). 

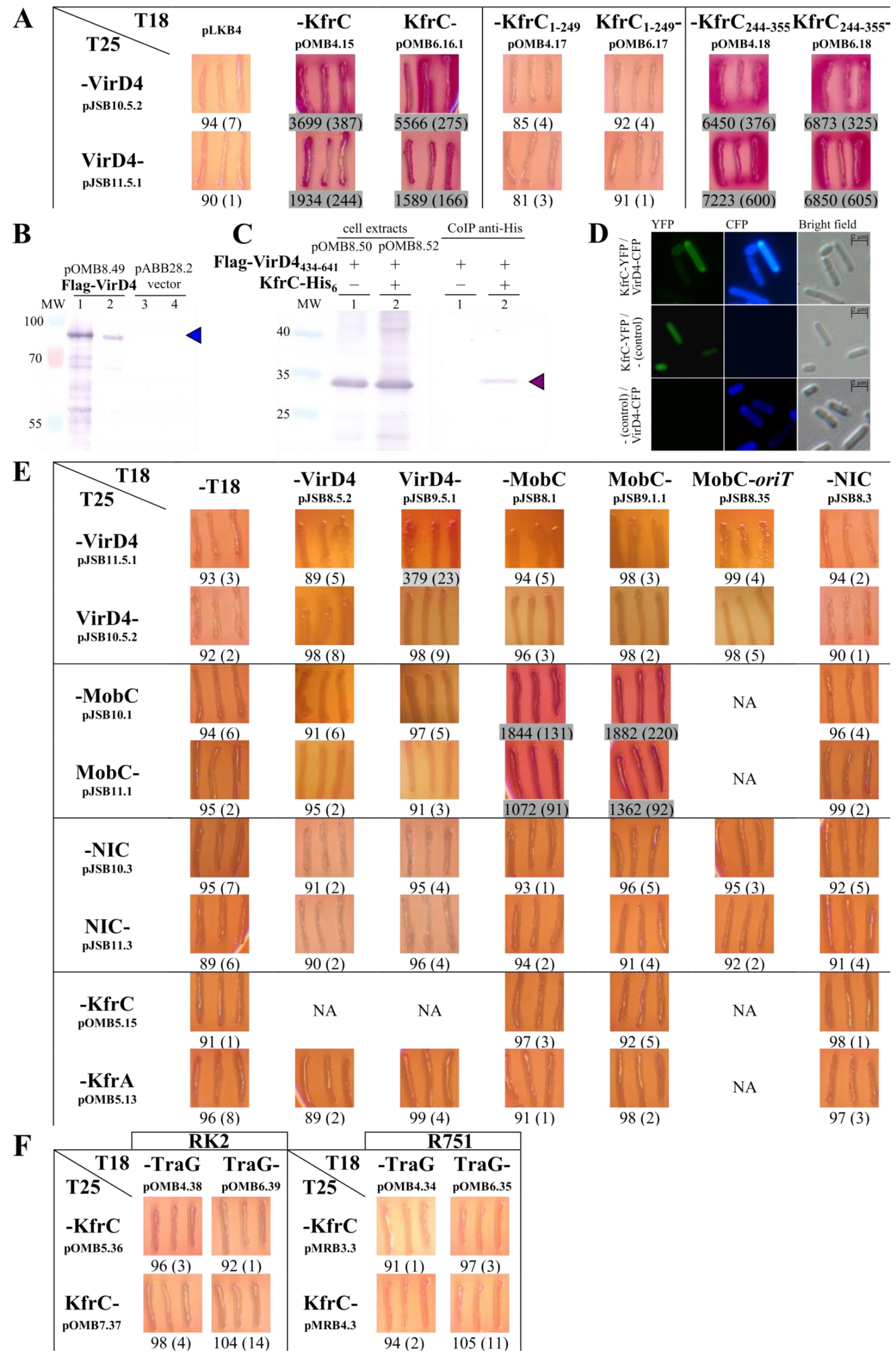
Figure 6. $\mathrm{KfrC}_{\mathrm{RA} 3}$ interactions with the conjugative coupling protein VirD4 and with the relaxosome proteins. (A) Mapping of the VirD4 $4_{\mathrm{RA3}}$ interaction domain within $\mathrm{KfrC}_{\mathrm{RA3}}$. The detailed description as in Figure 5. (B) Overproduction of FLAG-tagged VirD4 $4_{\text {RA3 }}$ (arrowhead) analyzed by SDS-PAGE and Western blotting with anti-FLAG antibodies. Lane 1 and 2-the cell debris and the soluble fraction of E. coli BL21(DE3) (pOMB8.49) extract, respectively. Lane 3 and 4 - the cell debris and the soluble fraction of E. coli BL21(DE3) (pABB28.2) extract, respectively. (C) Immunoprecipitation of complexes between $\mathrm{KfrC}_{\mathrm{RA} 3}$ and VirD4 $434-641$. FLAG-VirD4 $434-641$ was overproduced in BL21(DE3) either from pOMB8.50 (T7pflag-virD4434-641) or together with KfrC-His 6 from pOMB8.52 (T7p-flag-virD4 $434-641-k f r C-h i_{6}$ ). After immunoprecipitation with anti-His antibodies, proteins were separated by PAGE and screened with anti-FLAG antibodies in the Western blot procedure. Initial cellular extracts (left), proteins immunoprecipitated with the use of anti-His antibodies (right). Arrowhead, FLAG-VirD4 $434-641$ (26 kDa). Lane MW-molecular weight markers [kDa]. (D) Colocalization of KfrC RA3 YFP (pAKB2.70) and VirD4 ${ }_{\text {RA3 }}$-CFP (pOMB12.74) in E. coli DH5 $\alpha$ cells assayed by the fluorescence microscopy. Images were taken with the use of the appropriate filters for the two proteins in question. Bright field images served as the controls. (E) Interactions between RA3 relaxosome proteins NIC and MobC, the coupling protein VirD4, and Kfr proteins. The detailed description as in Figure 5. NA, not assayed in this set of tests. (F) Interactions between homologs of KfrC and VirD4 (TraG) of IncP plasmids, RK2 (IncP $\alpha$ ), and R751 (IncP $\beta$ ). Reciprocal plasmid combinations with TraG fusion proteins produced from the low-copy-number pKT25 and KfrC from pUT18 derivatives gave the same negative results.

Attempts to demonstrate interactions between full-length FLAG-VirD4 and KfrC-His 6 in the extracts of BL21(DE3) transformants by Co-IP were unsuccessful because VirD4 was found in the cell debris fraction after sonication (Figure 6B). Since the N-terminal part of VirD4 contains a putative transmembrane domain, it was decided to tag only the C-terminal part-VirD4 $434-641$. The KfrC-VirD4 interactions were then confirmed by Co-IP between KfrC-His 6 and FLAG-VirD4 $434-641$ (Figure 6C). FLAG-VirD ${ }_{434-641}$ was detected in the precipitate obtained with the use of anti-His antibodies. Finally, it was decided to see whether putative partners colocalize in a cell. Both $\mathrm{KfrC}$ and VirD4 were fluorescently labelled as KfrC-YFP and VirD4-CFP. Proteins were produced from the compatible expression vectors, pAKB2.70 and pOMB12.74, respectively, and introduced to the E. coli DH5 $\alpha$ strain separately or together (Figure 6D). KfrC-YFP gave a dispersed signal in the cells in the absence of the partner whereas VirD4-CFP formed bright foci at the poles in the majority of the cells in the presence and absence of KfrC. Notably, KfrC-YFP also formed foci close to the poles when VirD4-CFP was present in the cells, implicating that its polar positioning depended on VirD4.

As it was mentioned above (Figure $3 \mathrm{~A}$ ), the closest homolog of $\mathrm{KfrC}_{\mathrm{RA} 3}$ is $\mathrm{KfrC}_{\mathrm{RK} 2}$ of the IncP $\alpha$ plasmid [37]. However, the similarity concerns only the first 240 residues, which are lost from IncP $\beta$ representatives, e.g., KfrC of the $\mathrm{R} 751$ plasmid [38]. The 115-amino-acid polypeptide from the $\mathrm{C}$-terminus of $\mathrm{KfrC}_{\mathrm{RA} 3}$ has no homologs in the database. If the acquirement of a new $\mathrm{C}$-terminus by $\mathrm{KfrC}_{\mathrm{RA}} 3$ was the evolutionary way to accomplish a domain of interaction with VirD4, then both $\mathrm{KfrC}$ variants from $\mathrm{IncP} \alpha$ and IncP $\beta$ plasmids $\left(\mathrm{Kfr}_{\mathrm{R} 751}\right.$ is homologous to the $\mathrm{C}$-end of $\mathrm{KfrC}_{\mathrm{RK} 2}$ that is not present in $\mathrm{KfrC}_{\mathrm{RA}}$, Figure $3 \mathrm{~A}$ ) should be deprived of this ability. Hence, the $k f r C$ genes of RK2 and R751 were cloned into the BACTH system along with the cognate coupling proteins TraGs, homologs of VirD4 $4_{\text {RA3 }}$, and analyzed for interactions (Figure 6F). No interactions have been detected among KfrC and TraG proteins of RK2 and R751.

\subsection{The Interactions between the $\mathrm{Kfr}_{\mathrm{RA3}}$ Partners Involved in Two Modes of Plasmid Spreading}

Previously, it was established that partitioning proteins $\mathrm{KorB}_{\mathrm{RA} 3}$ and $\mathrm{Inc}_{\mathrm{RA} 3}$ dimerize and interact with each other [17] and that an alpha-helical, filamentous KfrA protein forms a complex with $\mathrm{KfrC}$ and interacts with $\mathrm{KorB}$ and IncC [18]. KfrC also heterodimerized

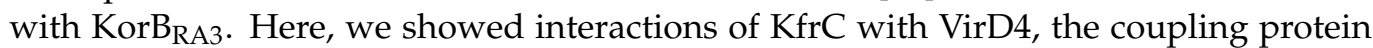
in the conjugative transfer process, as well as with VirB4, an ATPase participating in the inner membrane part of the transferosome. Using the BACTH system, we analyzed the interactions between the RA3 relaxosome proteins, the VirD4 protein, and the Kfr proteins. The RA3 relaxosome consists of the NIC relaxase and oriT [27]. Additionally, it was shown 
that MobC acts as an auxiliary protein potentiating the NIC cleavage at oriT [27]. NIC also collaborated with the MobC in the autoregulation of the mobC-nic operon [23].

After cloning of the nic and the mobC into the the BACTH vectors, we demonstrated that VirD4 interacted with neither NIC nor MobC and only weakly self-associated (Figure 6E). MobC, the autorepressor and the auxiliary transfer protein [23], strongly dimerized, but MobC-NIC interactions and dimerization of NIC were not detected. The presence of oriT did not facilitate interactions between the relaxase and the coupling protein that was observed in other conjugation systems [39-41]. Besides the KfrC-VirD4 interactions (Figure 6A), no associations of $\mathrm{KfrA}$ or $\mathrm{KfrC}$ and the relaxosome proteins were shown (Figure 6E). Altogether, these results suggest that the BACTH system is not the perfect tool to look at the formation of multicomponent complexes, especially if some of them act as the flexible/dynamic linkers. The interactions between the RA3 relaxosome components ought to be analyzed via other methods.

\subsection{The Interplay between the Active Partitioning and the Conjugative Transfer Processes}

The discovered interactions of $\mathrm{KfrC}$, probably when complexed with $\mathrm{KfrA}$, with KorB of the segrosome and the coupling protein VirD4 (or transferosome) raised a hypothesis of an interplay between mutually exclusive processes of vertical and horizontal spreading. The eight RA3 variants deprived of $k f r A, k f r C, k f r C-k f r A$, incC, virD4, nic, and two cis-acting sites, parS or oriT (as presented in Figures 1C and 7A), were constructed and used in the conjugation and stability experiments.

The additional RA3 construct had an insertion of a $1 \mathrm{~kb}$ fragment separating parS and oriT motifs (parS- $\mathbf{\nabla}$-oriT) to see whether close proximity of these motifs in the RA3 genome interferes with the binding of the segrosome and relaxosome complexes (Figure 1C).

All nine derivatives together with WT RA3 (control), were introduced into the E. coli DH $5 \alpha$ strain and tested for stability and frequency of conjugative transfer into the DH5 $\alpha$ Rif $^{\mathrm{r}}$ recipient. Stability assays showed that all tested deletion mutants except $\triangle i n c C$ were stably maintained in E. coli for 60 generations (Figures 7B and 2A for $k f r$ deletion mutants). Unexpectedly, the deletion of the parS region (seemingly the important cis-acting site in the active partition process [24]) did not influence the RA3 stability in E. coli. The presence of two additional KorB binding sites in the RA3 genome offers a plausible explanation of this result. Among nine RA3 deletion variants, only mutants virD4, nic, and $\triangle$ oriT mutants were significantly impaired in the conjugative transfer between the E. coli strains. Hence, no interference between conjugative transfer processes and stability functions was noticed in this host.

Different results were obtained during the analyses of the set of RA3 mutants in the P. putida KT2442 strain (Figures 7C and 2C, inset). WT RA3 was less stably maintained in the P. putida host than in E. coli being retained after 60 generations of growth without selection only in $30 \%$ of cells. Lack of any of Kfrs strongly destabilized RA3 and led to the loss of plasmid in $80 \%$ to $100 \%$ of cells after 20 generations. Lack of incC also caused a loss of the RA3 deletion derivative after 20 generations. The most spectacular results were observed when the RA3 variants were tested in the conjugation experiments. In the absence of KfrA, the RA3 conjugation frequency between P. putida strains decreased by more than six orders of magnitude whereas the lack of $\mathrm{KfrC}$ alone or both Kfrs had an opposite effect, increasing the conjugation frequency by approximately 10-fold. Separation of parS and oriT via kanamycin cassette led to a statistically insignificant increase in the conjugation frequency. Finally, deletion of inc $C$ had a detrimental effect not only on plasmid stability but also the frequency of the horizontal transfer and/or plasmid establishment. Similar results were obtained during interspecies conjugation between $P$. putida strains used as donors and the E. coli DH5 $\alpha$ strain as a recipient (bottom diagram in Figure 7C). 
A

RA3

$k f r C k f r A$ inc $C$

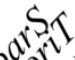

$\mathrm{RA} 3 \Delta k f r C$

RA $3 \Delta k f r A$

$\mathrm{RA} 3 \Delta(k f r C-A)$

$\mathrm{RA} 3 \Delta$ inc $C$

RA3 $\Delta$ nic

RA3 $\Delta$ virD4

B

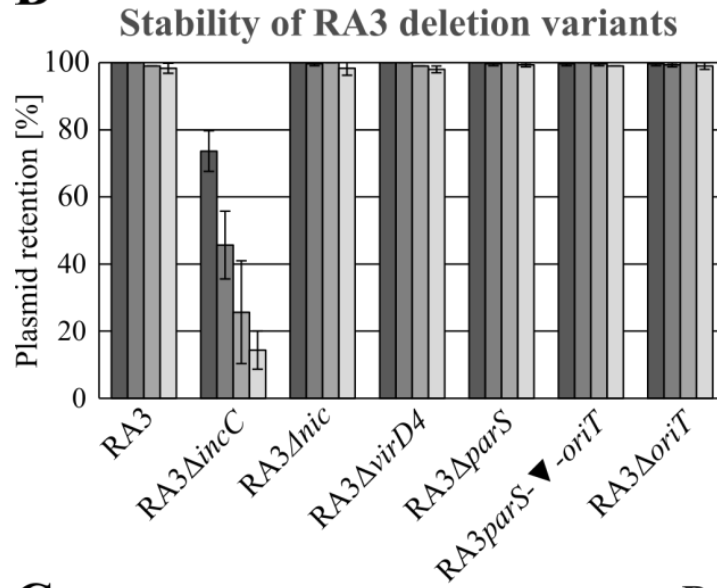

\section{E. coli DH5a}

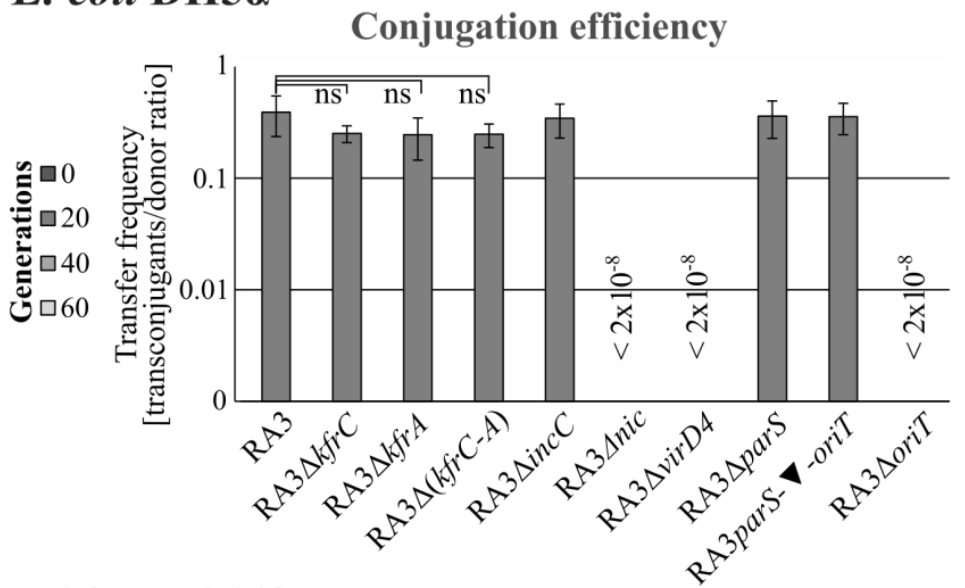

C

P. putida KT2442

Stability of RA3 deletion variants
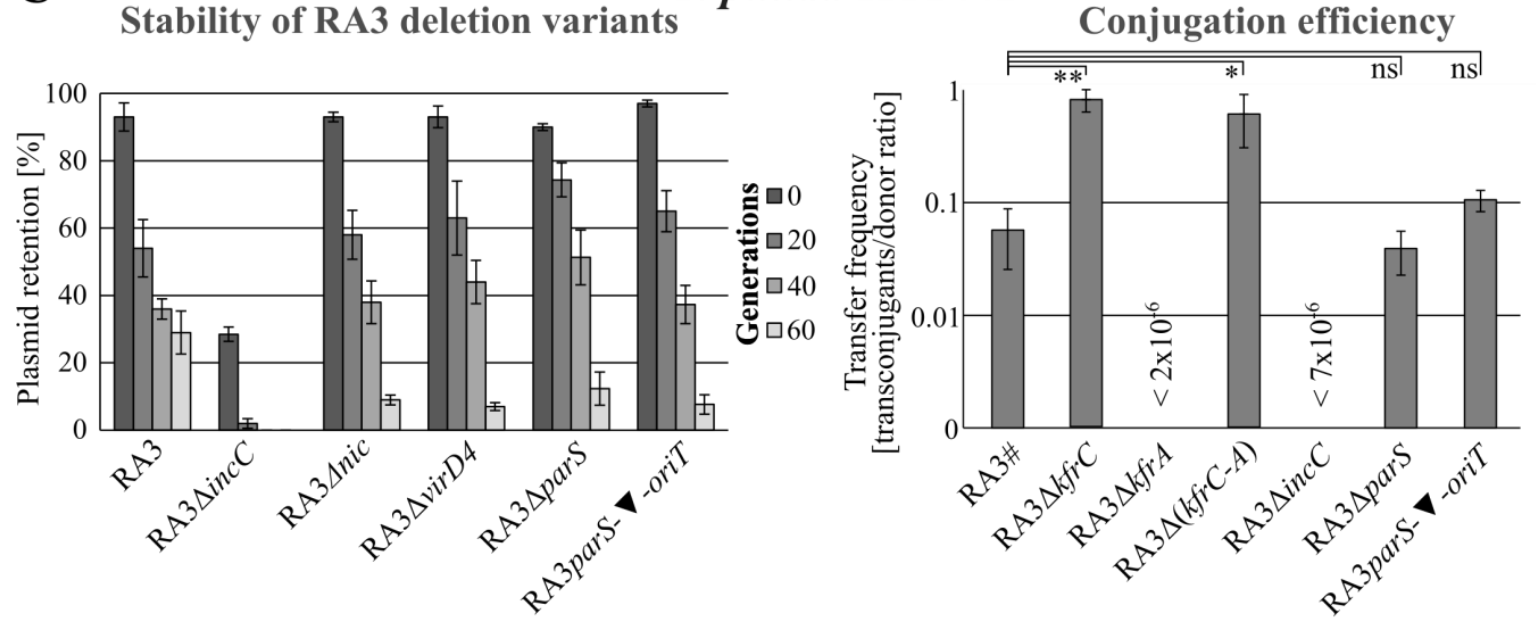

P. putida KT2442 - E. coli DH5a

Conjugation efficiency

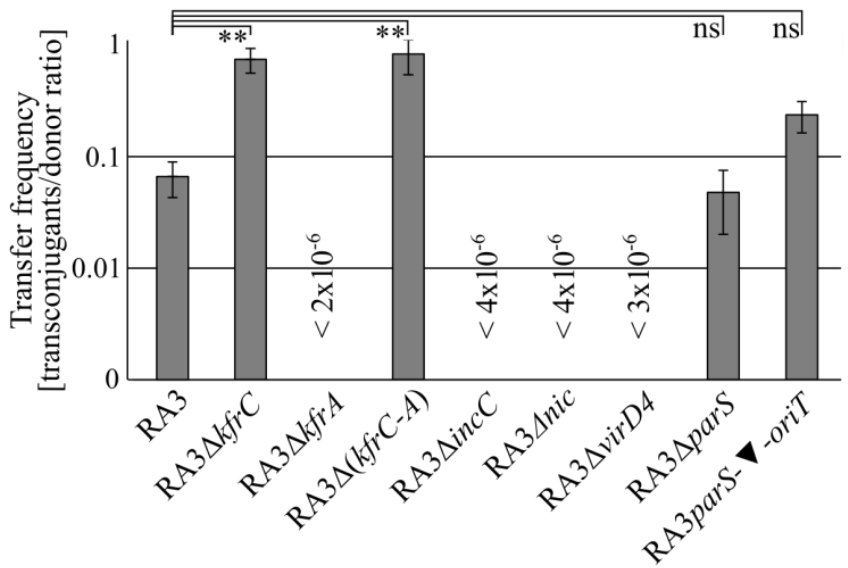


Figure 7. Role of $\mathrm{KfrC}_{\mathrm{RA} 3}$ in the plasmid stable maintenance and the efficiency of the conjugative transfer in $E$. coli and $P$. putida hosts. (A) Schematic presentation of RA3 variants used in these experiments. Other tested RA3 variants, RA3 $\Delta$ parS, RA3 3 oriT, and RA3 parS oriT insertional mutant, are depicted in Figure 1C. (B) Retention of RA3 variants in E. coli DH5 $\alpha$ strain and their conjugative transfer frequencies between $E$. coli strains. Segregation experiments were conducted for 60 generations without selection. Quantitative conjugation was done on the nitrocellulose filters and the transfer frequency was indicated on the semilogarithmic scale as the number of transconjugants per donor cell. Data represent mean \pm SD from three biological replicates. The differences in the frequency of the conjugative transfer between RA3 variants are not statistically significant (ns) ( $p$-value > 0.05 in Kruskal-Wallis one-way analysis of variance). (C) Retention of RA3 variants in P. putida KT2442 strain and their conjugative transfer frequency in the intra- and the interspecies spreading. RA3\# plasmid contains $\mathrm{Km}^{\mathrm{r}}$ cassette within integron. Introduction of RA3 conjugation-deficient variants to P. putida was done with the use of the helper strain E. coli DH5 $\alpha$ carrying pJSB1.24 with the RA3 conjugative transfer module and korC gene. Data represent mean \pm SD from three biological replicates. The statistically significant differences between WT RA3 and its variants with $p$-value $\leq 0.005$ or $<0.05$ (based on Kruskal-Wallis one-way ANOVA followed by Tukey's test of multiple comparisons) are indicated by two or one asterisk, respectively.

\section{Discussion}

Studies on the alpha-helical KfrA protein [16] have suggested its role in the stability of IncP plasmids, together with $\mathrm{KfrC}$, is encoded in the same operon [13]. It was shown that the KfrA of R751 interacted with $\mathrm{KfrC}$ using a linker, $\mathrm{KfrB}$ [13]. In the RA3 plasmid of the IncU group, KfrC could interact directly not only with KfrA but also with KorB (Figure 8A), one of the components of the active partition system [18]. It was shown that $\mathrm{KfrA}_{\mathrm{RA} 3}$ had the ability to form filaments [29] and interacted with both components of the partition apparatus, KorB and IncC. Hence, the accessory role of a scaffold built of Kfr complexes in the segregation of plasmid molecules to the progeny cells in a species-dependent manner was envisaged [18].
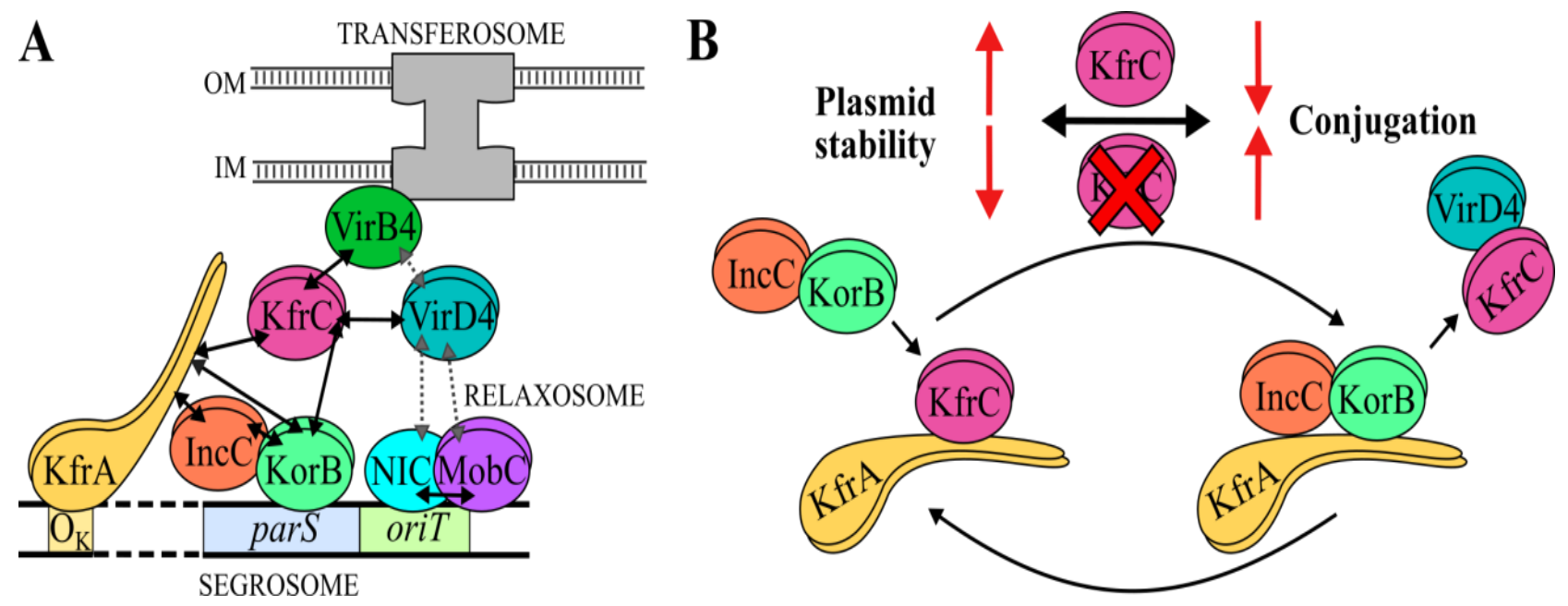

Figure 8. Interactions between the Kfr proteins, segrosome, relaxoxosome, and transferosome in RA3. (A) Model of the complexes built at parS-oriT region of RA3. (B) KfrC acts as a switch between the horizontal and the vertical spreading of RA3 plasmid. The established protein-protein interactions (this work, $[17,18]$ ) are indicated by solid arrows. Putative interactions are depicted by the broken-line arrows.

The studies on $k f r A$ and $k f r C$ conducted on the stability module cloned into a highly unstable heterologous replicon $[18,26]$ proved an important role of both proteins in the stable maintenance of the test plasmid in the E. coli, P. putida, A. tumefaciens, and C. necator strains. It was also shown that the KfrA DNA binding activity was vital to support plasmid stability [18]. Here, we decided to look at the effects of the deletions of $k f r C, k f r A$ operon, or both $(\Delta k f r C-k f r A)$ in the RA3 background. In E. coli, the presence of any of these three derivatives led to the growth retardation, a slight increase in the generation time, and, 
in the case of RA3 $\Delta k f r C$, to the formation of filamentous cells. Despite these changes, all three variants were very stably maintained for at least 60 generations of growth without selection in clear contrast to the results of the test plasmid pESB36.44 $(\triangle k f r A)$ based on the heterologous RK2 minireplicon $[18,26]$. It demonstrated that in E. coli, in the context of the whole RA3 genome, the Kfr proteins did not play vital roles in the segregation of RA3. The very active conjugation system or easily adaptable RA3 replication system may compensate for the difference the lack of Kfr proteins imposes on the plasmid retention. In other tested hosts, e.g., P. putida, A. veronii, or C. necator, the effects of Kfr deficiencies were much stronger not only on the growth rate but also on the stable maintenance and clearly were species-specific (Figure 2).

$\mathrm{KfrC}$ belongs to the alpha-helical proteins with two-domain structures. The N-terminal part with phosphoribosyltransferase (PRT)-type I domain (Pfam: PF00156) is responsible for its "toxicity" when in excess. The results of screening of E. coli and A. veronii genomic libraries strongly suggested that $\mathrm{KfrC}_{\mathrm{RA} 3}$ was part of the phosphometabolomes of the hosts. The metabolic role of $\mathrm{KfrC}$ in various hosts is under investigation. This initial libraries' screening also revealed the interactions between $\mathrm{KfrC}_{\mathrm{RA} 3}$ and the various membrane-bound proteins, implicating at least temporal positioning of $\mathrm{KfrC}$ close to a cellular membrane. Its polar cell localization in the presence of VirD4 was demonstrated (Figure 6D).

The $\mathrm{KfrC}_{\mathrm{RA} 3} \mathrm{C}$-terminal domain of 112 residues seems to be multifaceted. Its involvement in the dimerization, in the interactions with the partition protein KorB, and the coupling protein VirD4 opens new possibilities of the $\mathrm{KfrC}$ role in the RA3 plasmid biology (Figure 8A).

The RA3 deletion derivatives in $k f r$ genes were not only less stable than WT RA3 in $P$. putida but also demonstrated the altered conjugation frequency between $P$. putida strains and P.-putida- E. coli strains. The effect was very strong when KT2442 RA3( $\Delta k f r A)$ was used as a donor. The conjugation frequency was more than six orders of magnitude lower than for WT RA3. Significantly, the removal of $k f r C$ or $k f r A-k f r C$ stimulated 10-fold the transfer frequency of the analyzed RA3 derivatives in comparison to the WT RA3 (Figure 7C), implicating a negative role of $\mathrm{KfrC}$ in the conjugative transfer efficiency and a requirement for $\mathrm{KfrA}$ only when $\mathrm{KfrC}$ was present. The insignificant variation in the number of transconjugants of RA3 with the parS and oriT sites separated by a $1 \mathrm{~kb}$ insertion suggested that the closeness of these two important cis-acting sites in the WT RA3 did not affect the transfer initiation process despite the fact that they had to accommodate next to each other two large protein complexes, segrosome and relaxosome.

Our previous studies on the RA3 relaxosome demonstrated an auxiliary role of the MobC protein. The MobC binding to $\mathrm{O}_{\mathrm{M}}$ in the mobc $p$ had not only an autoregulatory role in the mobC-nic expression but it increased the nicking activity of NIC more than 1000-fold and in turn stimulated the transfer [23]. Reciprocally, the interaction of NIC with its binding site (IR3, Figure 1C) enhanced the MobC repressor action of mobCp [27]. The BACTH studies concerning intermolecular interactions within the RA3 relaxosome demonstrated neither NIC interactions with MobC nor with VirD4 (Figure 6E). The MobC dimerized efficiently but did not associate with VirD4 as it was observed for the auxiliary proteins in other conjugative systems [39-41]. Other experimental approaches are needed to elucidate the structure of the RA3 relaxosome. Hence, lack of the observed interactions between $\mathrm{Kfr}$ and relaxosome proteins does not exclude the possibility of their occurrence in the cells.

In this study, a new VirD4 $4_{\mathrm{RA} 3}$ partner was found, the $\mathrm{KfrC}$ protein that somehow linked the conjugation with the active partition process not only by interactions with VirD4 but also VirB4 ATPase (Figure 8A), an important energy supplier for the transferosome [36]. VirD4s have multidomain structures [39] with (i) an N-terminal transmembrane domain responsible for the spatial positioning and interactions with the transferosome inner membrane complex (IMC), (ii) a cytoplasm facing the middle part with the ATPase domain (energy supplier), and (iii) a seven-helix motif called the all- $\alpha$ domain (AAD) responsible for recruiting and docking a relaxase with the covalently bound transfer DNA. 
The variable-length (iv) cytosolic C-terminal domains are typically enriched in the acidic residues $[42,43]$ and are assumed to evolve to expand a range of protein effectors being transferred by T4SS as well as to control presentation of effectors to the system [39]. Notably, according to the BACTH library screening, there are two fragments of VirD4 ${ }_{\mathrm{RA} 3}$ interacting with $\mathrm{KfrC}_{\mathrm{RA} 3}$ : the internal hydrophobic polypeptide $\operatorname{VirD} 4_{244-283}$ and the C-terminal 47 residues. Finding that VirD4 of RA3 was capable of interactions with $\mathrm{KfrC}_{\mathrm{RA} 3}$, whereas TraGs, VirD4 homologs of IncP plasmids, did not interact with the cognate $\mathrm{KfrCs}$, correlated with VirD4 $4_{\text {RA3 }}$ having an extended highly acidic C-terminus in comparison to the IncP homologs (Figure S3). On the other hand, $\mathrm{KfrC}_{\mathrm{RA} 3}$ also differs from the IncP homologs in its C-terminal part of the 115-residue polypeptide that exhibits the high content of the polar residues (45\%). This fragment, unique for $\mathrm{KfrC}_{\mathrm{RA} 3}$, (Figure $3 \mathrm{~A}$ ) was shown to be involved in the dimerization and binding of both KorB and VirD4.

Previously, we showed that the conjugative transfer process of RA3 was subjected to complex multilayered control mechanisms. The three conjugative transfer operons were strongly repressed by the global and the local repressors at least in E. coli. The mobC-nic operon is autoregulated by MobC and NIC [27]. The longest operon orf33-traC3, encoding most of the transferosome components, is regulated by the global regulator KorC in cooperation with the so far unidentified product of the transfer module [25]. The cross-talk between stability and conjugative functions is also potentiated by the fact that in this long transcriptional unit there is the internal promoter, orf $23 p$, negatively controlled by the second global regulator, active partition protein KorB, bound at the distant $\mathrm{O}_{\mathrm{B}}$ [17]. Divergently oriented, orf34p of the tricistronic operon orf34-orf36, is very efficiently repressed by KorC. Here, we showed that at the top of this transcriptional regulation there are protein-protein interactions, $\mathrm{KfrC}-\mathrm{VirD} 4$, that decrease the efficiency of the conjugative transfer process. Our transcriptional studies conducted in different hosts showed that the highest level of gene expression in the stability module was detected for the partition operon incC-korB-orf11 with the korC-kfrC operon being the second in line [26]. Constitutive expression of the $k o r C-k f r C$ operon at the significant level may determine their importance in the control of the conjugative transfer besides its important role in the plasmid partition process.

Our model implicates that $\mathrm{KfrC}$ may improve the plasmid segregation by bringing the segrosome complex to the filamentous KfrA scaffold due to its ability to bind KorB and KfrA. KorB may outcompete KfrC for the KfrA binding since both proteins interact preferentially with the $\mathrm{KfrA}_{54-177}$ region [18]. The release of $\mathrm{KfrC}$ from the KfrA filamentous network allows it to interact with VirD4 and, in effect, to interfere with the efficient transfer of relaxosome to the transferosome at least in the P. putida cells. Significantly, the C-terminal dimerization domain of $\mathrm{KfrC}$ is involved in the interactions not only with $\mathrm{KorB}$ (segrosome) but also with VirD4, so it may provide a spatiotemporal switch between two processes responsible for the various modes of RA3 spreading, vertical and horizontal (Figure 8B). The strength of KorB-KfrC-VirD4 interactions may also be species-specific due to additional factors involved.

The interplay of two aspects of a plasmid physiology, stable maintenance and the conjugative expansion, was brought to the attention of researchers via the analysis of an atypical plasmid stabilization system, $s t b A B C$, of the conjugative BHR plasmid R388 of the IncW incompatibility group [44]. Deletion of the $s t b A$ encoding a DNA binding protein led to the plasmid instability and the increased transfer frequency. Oppositely, the deletion of an ATPase encoding $s t b B$ did not affect the plasmid maintenance, but it abolished conjugative transfer. It was postulated that the defects in both plasmid maintenance and transfer were a consequence of changes in the positioning of the $s t b$ plasmid mutants in the cells [44].

The correlation between the active partition and the conjugative transfer processes was also postulated for the low-copy-number conjugative R1 plasmid of the IncFII incompatibility group [45]. R1 is a narrow-host-range plasmid with the type II active partitioning system [7]. It was shown that ParM, an actin-like ATPase, interacted with TraD, a homolog 
of VirD4 (the coupling protein), TraC (an ATPase, a homolog of VirB4), and TraI (the relaxase). TraI also interacted with the second component of the partition system, ParR, a DNA binding protein. Importantly ParM and TraI mutually increased their enzymatic activities of NTPase and relaxase, respectively. Thus, in the case of R1, the functional collaboration of Par components with the relaxosome/transferosome complex appeared optimal for its vertical and lateral modes of dissemination.

These examples and our work indicate the importance of the integration of plasmid maintenance function with the conjugation process, although it may differ in the mechanisms, e.g., cooperation and coordination as observed for R1 and R388 or the partial exclusion as in the RA3 system. The requirements for adaptation to an environment and a host range may drive these evolutionary changes.

\section{Materials and Methods}

\subsection{Bacterial Strains and Growth Conditions}

The E. coli strains used were: $\mathrm{DH} 5 \alpha\left[\mathrm{F}^{-}(\phi 80\right.$ dlacZ $\triangle M 15)$ recA1 endA1 gyrA96 thi-1 hsdR17 $\left(\mathrm{r}_{\mathrm{K}}{ }^{-} \mathrm{m}_{\mathrm{K}}{ }^{+}\right)$supE44 relA1 deoR $\Delta\left(\right.$ lacZYA-argF)U196], BL21(DE3) [ $\mathrm{F}^{-}$ompT hsd $\mathrm{B}_{\mathrm{B}}\left(\mathrm{r}_{\mathrm{B}}{ }^{-}\right.$

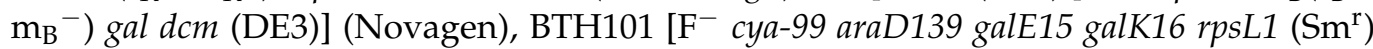
hsdR2 mcrA1 mcrB1] [34], BW25113 [lacl ${ }^{\mathrm{q}} \mathrm{rrnB}_{\mathrm{T} 14} \Delta \mathrm{LacZ}_{\mathrm{WJ16}}$ hsdR514 $\triangle$ araBA-DAH33 $\triangle \mathrm{rhaBADLD78]} \mathrm{[30],} \mathrm{and} \mathrm{S17-1} \mathrm{[recA} \mathrm{pro} \mathrm{hsdR} \mathrm{RP4-2-Tc::Mu-Km::Tn7]} \mathrm{[46].} \mathrm{The} \mathrm{rifampin-}$ resistant mutants of $A$. tumefaciens LBA1010R [47] and P. aminovorans JCM7685 [48] were kindly provided by D. Bartosik, University of Warsaw, Poland, C. necator JMP228 was kindly provided by K. Smalla, Julius Kühn-Institut, Federal Research Institute for Cultivated Plants, Germany, and P. putida KT2442 was kindly provided by C.M. Thomas, University of Birmingham, United Kingdom. The spontaneous Rif ${ }^{\mathrm{r}}$ mutant of $A$. veronii (kindly provided by M. Gniadkowski as an environmental $A$. hydrophila strain) was isolated in the laboratory.

Bacteria were generally grown in L broth [49] or on L agar (L broth with $1.5 \% w / v$ agar) at $37^{\circ} \mathrm{C}$ or at $28{ }^{\circ} \mathrm{C}$ (A. tumefaciens, C. necator, P. aminovorans, P. putida, and E. coli BTH101). MacConkey agar base (BD Difco) or M9 medium supplemented with $1 \%$ maltose were used in the bacterial adenylate cyclase-based two-hybrid system (BACTH) and in the library screening, respectively [50]. If needed, media were supplemented with X-gal (5bromo-4-chloro-3-indolyl- $\beta$-d-galactopyranoside) $\left(40 \mu \mathrm{g} \mathrm{mL}^{-1}\right)$ for blue/white screening, IPTG (isopropyl- $\beta$-d-thiogalactopyranoside) for tacp induction or appropriate antibiotic(s): chloramphenicol $\left(10 \mu \mathrm{g} \mathrm{mL}^{-1}\right.$ for E. coli, $50 \mu \mathrm{g} \mathrm{mL}{ }^{-1}$ for A. tumefaciens, $150 \mu \mathrm{g} \mathrm{mL}^{-1}$ for C. necator), kanamycin (50 $\mathrm{g} \mathrm{mL}^{-1}$ for E. coli, $20 \mu \mathrm{g} \mathrm{mL} \mathrm{m}^{-1}$ for P. aminovorans and P. putida), tetracycline (50 $\mathrm{g} \mathrm{mL}^{-1}$ for P. putida, $10 \mu \mathrm{g} \mathrm{mL}^{-1}$ for other strains), or penicillin (sodium salt) $\left(150 \mu \mathrm{g} \mathrm{mL}^{-1}\right.$ in liquid media and $300 \mu \mathrm{g} \mathrm{mL}^{-1}$ for agar plates), rifampin $\left(100 \mu \mathrm{g} \mathrm{mL}^{-1}\right)$.

\subsection{Plasmid DNA Isolation, Analysis, DNA Amplification, and Manipulation}

Plasmid DNA was isolated and manipulated using standard methods [50] or kits using manufacturers' instructions. All new plasmid constructs were verified by DNA sequencing at the Laboratory of DNA Sequencing and Oligonucleotide Synthesis, Institute of Biochemistry and Biophysics Polish Academy of Science. The list of plasmids used and constructed in this study is presented in Table 3. Oligonucleotides are listed in Table 4. 
Table 3. Plasmids used in this study.

\begin{tabular}{|c|c|}
\hline \multicolumn{2}{|c|}{ Plasmids Provided by Others } \\
\hline Designation & Relevant Features or Description \\
\hline pABB19 & ori $_{\mathrm{MB} 1}, \mathrm{Ap}^{\mathrm{r}}$, transcriptional terminator Tpro/Tlyz P1 [51] \\
\hline pABB28.2 & pET28a with his-tag replaced by flag-tag [52] \\
\hline pAKB2.55 & pGBT30 with $k f r C$ without a stop codon (IBB) ${ }^{a}$ \\
\hline pAKB2.70 & ${\text { pGBT30 with } k f r C_{\text {RA3 }}-y f p(\text { IBB })^{\text {a }}}$ \\
\hline pAKB7.5 & ori $_{\mathrm{MB} 1}, \mathrm{Km}^{\mathrm{r}}{ }$,parS-ori $\mathrm{T}_{\mathrm{RA} 3}$ (RA3 coordinates $\left.9397-9854 \mathrm{nt}\right)$ [24] \\
\hline pAKB16.50 & pLKB4 cyaT18-korB RA3 $_{17]}$ \\
\hline pAKB16.50N & 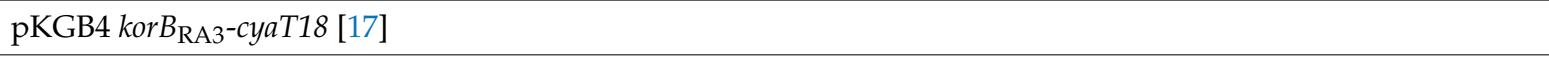 \\
\hline pAMB8 & pBBR1MCS-3 modified in tet $M$ to remove EcoRI site (IBB) ${ }^{a}$ \\
\hline pBBR1MCS & IncA $/ \mathrm{C}, \mathrm{Cm}^{\mathrm{r}}$, BHR cloning vector $[53]$ \\
\hline pBBR1MCS-2 & IncA/C, $\mathrm{Km}^{\mathrm{r}} \mathrm{BHR}$ cloning vector [54] \\
\hline pBGS18 & ori $_{\mathrm{MB} 1}, \mathrm{Km}^{\mathrm{r}}$, cloning vector $[55]$ \\
\hline pESB5.58 & pGBT30 with tacp-kfrA [18] \\
\hline pET28a & ori $_{\mathrm{MB} 1}, \mathrm{Km}^{\mathrm{r}}, \mathrm{T} 7 p$, lacO, $\mathrm{His}_{6}$-tag, $\mathrm{T} 7 \mathrm{tag}$ (Novagen) \\
\hline pET28mod & pET28a derivative, $\mathrm{T} 7 \mathrm{tag}$ removed [56] \\
\hline pGBT30 & ori $_{\mathrm{MB} 1}, \mathrm{Ap}^{\mathrm{r}}$, lacI $^{q}$, tacp expression vector [57] \\
\hline pJSB8.5.2 & pLKB4 cyaT18-virD4 (IBB) $^{\text {a }}$ \\
\hline pJSB9.5.1 & pKGB4 virD4-cyaT18 (IBB) ${ }^{\text {a }}$ \\
\hline pJSB10.5.2 & pLKB2 cyaT25-virD4 (IBB) $^{\text {a }}$ \\
\hline pJSB11.5.1 & pKGB5 virD4-cyaT25 (IBB) ${ }^{\text {a }}$ \\
\hline pKAB20 & 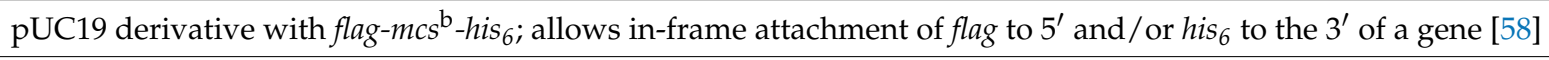 \\
\hline pKAB28 & pET28mod with deletion of $h i_{6}$-tag and EcoRI site adjacent to RBS [57] \\
\hline pKAB28.7 & pET28mod derivative with $h_{i s_{6}}-m c s^{b}[58]$ \\
\hline pKD13 & template plasmid for gene disruption [30] \\
\hline pKD46 & ori $_{\mathrm{R} 101}$, araBp-gam-bet-exo, repA101(ts), Ap ${ }^{\mathrm{r}}$, lambda Red recombinase expression plasmid [30] \\
\hline pKGB4 & ori $_{\text {ColE1 }}$, pUT18 with modified mcs, lacp- mcs ${ }^{b}-c y a T 18, \mathrm{Ap}^{\mathrm{r}}$ (IBB) ${ }^{\mathrm{a}}$ \\
\hline pKGB5 & ori $_{\mathrm{p} 15}$, pKNT25 with modified $m c s$, lacp mcs $^{\mathrm{b}}-c y a T 25, \mathrm{Km}^{\mathrm{r}}(\mathrm{IBB})^{\mathrm{a}}$ \\
\hline pKT25-zip & pKT25 derivative encoding CyaT25 in translational fusion with leucine zipper of GCN4 [34] \\
\hline pLKB2 & ori $_{\mathrm{p} 15}, \mathrm{pKT} 25$ with modified $m c s$, lacp-cyaT25- $m c s^{\mathrm{b}}, \mathrm{Km}^{\mathrm{r}}[59]$ \\
\hline pLKB4 & ${ }^{o r i}{ }_{\mathrm{ColE}}$, pUT18C with modified mcs, lacp-cyaT18- $m c s^{\mathrm{b}}$, Ap ${ }^{\mathrm{r}}[59]$ \\
\hline pMRA1.3 & $\mathrm{pLKB}$ with cyaT18-kfrC $\mathrm{R}_{\mathrm{R} 51}$ (IBB) $^{\mathrm{a}}$ \\
\hline pMRB2.3 & pKGB4 with $k f r C_{\mathrm{R} 751^{-c y a T 18}(\mathrm{IBB})^{\mathrm{a}}}$ \\
\hline pMRB3.3 & 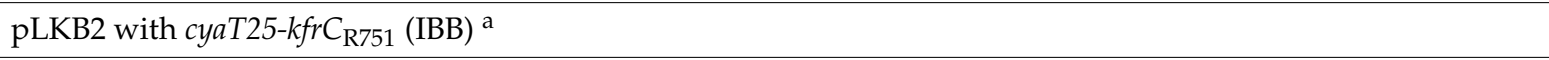 \\
\hline pMRB4.3 & pKGB5 with $k f r C_{\mathrm{R} 751-c y a T 25}(\mathrm{IBB})^{\text {a }}$ \\
\hline pOMB3.104 & pUC18 derivative with parS P1 prophage (IBB) ${ }^{a}$ \\
\hline pOMB4.13 & pLKB4 with cyaAT18-kfrA [18] \\
\hline pOMB4.15 & pLKB4 with cyaAT18-kfrC [18] \\
\hline pOMB5.13 & pLKB2 with cyaAT25-kfA [18] \\
\hline pOMB5.15 & pLKB2 with cyaAT25-kfrC [18] \\
\hline pOMB6.14 & pKGB4 with kfrA-cyaAT18 [18] \\
\hline pOMB6.16.1 & pKGB4 with kfrC-cyaAT18 [18] \\
\hline
\end{tabular}


Table 3. Cont.

\begin{tabular}{|c|c|}
\hline \multicolumn{2}{|c|}{ Plasmids Provided by Others } \\
\hline Designation & Relevant Features or Description \\
\hline pOMB7.14 & pKGB5 with kfrA-cyaAT25 [18] \\
\hline pOMB7.16.1 & pKGB5 with $k f r C$-cyaAT25 [18] \\
\hline pOMB9.80 & pGBT30 with $k f r A_{\mathrm{RA} 3}-c f p(\mathrm{IBB})^{\text {a }}$ \\
\hline pUC18 & ori $_{\mathrm{MB} 1}, \mathrm{Ap}^{\mathrm{r}}$, cloning vector $[60]$ \\
\hline pUT18C-zip & pUT18C derivative encoding CyaT18 in translational fusion with leucine zipper of GCN4 [34] \\
\hline $\mathrm{R}^{2} 51 \mathrm{TC}^{\mathrm{R}}$ & $\operatorname{IncP} \beta(\operatorname{IncP}-1 \beta)^{c}, \mathrm{Tc}^{\mathrm{r}}$-derivative of R751 [38] \\
\hline RA3 & IncU $(\operatorname{IncP}-6)^{\mathrm{c}}, \mathrm{Cm}^{\mathrm{r}}, \mathrm{Sm}^{\mathrm{r}}, \mathrm{Su}^{\mathrm{r}}$ (F. Hayes) \\
\hline RK2 & $\operatorname{IncP} \alpha(\operatorname{IncP}-1 \alpha)^{c}, \mathrm{Ap}^{\mathrm{r}}, \mathrm{Km}^{\mathrm{r}}, \mathrm{Tc}^{\mathrm{r}}$ (C.M. Thomas) \\
\hline \multicolumn{2}{|c|}{ Plasmids Constructed during This Work } \\
\hline Designation & Relevant Features or Description \\
\hline pESB5.88 & pGBT30 with tacp-kfrC; annealed oligonucleotides 28 and 29 inserted between Xba-Sall of pAKB2.55 \\
\hline pESB5.90 & $\begin{array}{l}\text { pGBT30 with } t a c p-k f r C \text { without a stop codon; annealed oligonucleotides } 6 \text { and } 7 \text { inserted between Xba-SalI of } \\
\text { pAKB2.55 }\end{array}$ \\
\hline pESB10 & $\begin{array}{l}\text { pBBR1MCS-2 lacI }{ }^{q} \text { tacp with transcriptional terminator T1/T2 }{ }_{r r n B} ; \mathrm{PCR} \text { product obtained with primers } 36 \text { and } 37 \\
\text { on E. coli genomic DNA inserted as XhoI-KpnI fragment between SalI-KpnI sites }\end{array}$ \\
\hline pESB11 & $\begin{array}{l}\text { pOMB12.0 derivative with transcriptional terminator T1/T2 }{ }_{r r n B} ; \mathrm{PCR} \text { fragment obtained with primers } 36 \text { and } 37 \\
\text { on E. coli genomic DNA inserted between XhoI-KpnI sites }\end{array}$ \\
\hline pESB11.58 & pESB11 with tacp-kfrA; EcoRI-SalI fragment from pESB5.58 inserted between EcoRI-XhoI sites \\
\hline pESB15 & pET28a with annealed oligonucleotides 30 and 31 inserted between NcoI and BamHI sites \\
\hline pESB15.90 & pESB15 with $k f r C-h i s_{6} ;$ EcoRI-HindIII fragment from pESB5.90 \\
\hline pJSB1.4 & $\begin{array}{l}\text { pBGS18 with the mobCp-mobC-nic; PCR fragment obtained with primers } 26 \text { and } 5 \text { on RA3 template inserted } \\
\text { between EcoR-SalI sites (RA3 coordinates } 9437-11355 \mathrm{nt} \text { ) }\end{array}$ \\
\hline pJSB1.5.2 & $\begin{array}{l}\text { pBGS18 with virD4; PCR fragment obtained with primers } 44 \text { and } 45 \text { on RA3 template cloned between the } \\
\text { BamHI-KpnI sites (RA3 coordinates } 18230-16305 \mathrm{nt} \text { ) }\end{array}$ \\
\hline pJSB1.8 & pBGS18 with TraRA3; pJSB1.4 with SmaI-SalI fragment of RA3 plasmid (RA3 coordinates 10733-22925 nt) \\
\hline pJSB1.24 & $\begin{array}{l}\text { pBGS18 with Tra } \text { RA3 } \text {-korCp-korC; PCR fragment korCp-korC obtained with primers } 2 \text { and } 3 \text { (RA3 coordinates } \\
\text { 3093-3705) inserted into pJSB1.8 }\end{array}$ \\
\hline pJSB8.1 & $\begin{array}{l}\text { pLKB4 with cyaT18-mobC; PCR fragment obtained with primers } 22 \text { and 23, cloned between the EcoRI-HincII sites } \\
\text { (RA3 coordinates 9837-10455 nt) }\end{array}$ \\
\hline pJSB8.3 & $\begin{array}{l}\text { pLKB4 with cyaT18-nic; PCR fragment obtained with primers } 25 \text { and } 26 \text { cloned between the EcoRI-HincII sites } \\
\text { (RA3 coordinates 10360-11355 nt) }\end{array}$ \\
\hline pJSB8.5.2 & pLKB4 with cyaT18-virD4; fragment BamHI-KpnI from pJSB1.5.2 cloned into pLKB4 \\
\hline pJSB8.35 & $\begin{array}{l}\text { pLKB4 with cyaT18-mobC-oriT } T_{\mathrm{RA} 3} \text {; SmaI-HincII fragment of pAKB7.5 carrying parS-oriT cloned into PvuII site of } \\
\text { pJSB8.1 }\end{array}$ \\
\hline pJSB9.1.1 & $\begin{array}{l}\text { pKGB4 with mobC-cyaT18; PCR fragment obtained with primers } 22 \text { and } 24 \text { cloned between EcoRI-SacI sites, (RA3 } \\
\text { coordinates } 9837-10364 \mathrm{nt})\end{array}$ \\
\hline pJSB9.5.1 & $\begin{array}{l}\text { pKGB4 with virD4-cyaT18; PCR fragment obtained with primers } 44 \text { and } 46 \text { cloned between BamHI-SacI sites (RA3 } \\
\text { coordinates } 18230-16308 \mathrm{nt} \text { ) }\end{array}$ \\
\hline pJSB10.1 & $\begin{array}{l}\text { pLKB2 with cyaT25-mobC; PCR fragment EcoRI-HincII obtained with primers } 22 \text { and 23, cloned between the } \\
\text { EcoRI-SmaI sites (RA3 coordinates 9837-10455 nt) }\end{array}$ \\
\hline pJSB10.3 & $\begin{array}{l}\text { pLKB2 with cyaT25-nic; PCR fragment EcoRI-HincII obtained with primers } 25 \text { and } 26 \text { cloned between EcoRI-SmaI } \\
\text { sites (RA3 coordinates10360-11355 nt) }\end{array}$ \\
\hline pJSB10.5.2 & $\begin{array}{l}\text { pLKB2 with cyaT25-virD4; PCR fragment obtained with primers } 44 \text { and } 45 \text { cloned between BamHI-KpnI sites (RA3 } \\
\text { coordinates18230-16305 nt) }\end{array}$ \\
\hline
\end{tabular}


Table 3. Cont.

\begin{tabular}{|c|c|}
\hline \multicolumn{2}{|c|}{ Plasmids Constructed during This Work } \\
\hline Designation & Relevant Features or Description \\
\hline pJSB11.1 & $\begin{array}{l}\text { pKGB5 with mobC-cyaT25; PCR fragment obtained with primers } 22 \text { and } 24 \text { cloned between EcoRI-SacI sites (RA3 } \\
\text { coordinates } 9837-10364 \mathrm{nt} \text { ) }\end{array}$ \\
\hline pJSB11.3 & $\begin{array}{l}\text { pKGB5 with nic-cyaT25; PCR fragment obtained with primers } 25 \text { and } 27 \text { cloned between EcoRI-SacI sites (RA3 } \\
\text { coordinates 10360-11352 nt) }\end{array}$ \\
\hline pJSB11.5.1 & $\begin{array}{l}\text { pKGB5 with virD4-cyaT25; PCR fragment obtained with primers } 44 \text { and } 46 \text { cloned between BamHI-SacI sites (RA3 } \\
\text { coordinates } 18230-16308 \mathrm{nt} \text { ) }\end{array}$ \\
\hline pOMB1.17 & $\begin{array}{l}\text { pBGS18 with } k f r C_{1-249} \text {; PCR product amplified on RA3 template with primers } 8 \text { and } 9 \text { inserted between EcoRI-SalI } \\
\text { sites (RA3 coordinates: 3692-4438) }\end{array}$ \\
\hline pOMB1.18 & $\begin{array}{l}\text { pBGS18 with } k f r C_{244-355} \text {; PCR product amplified on RA3 template with primers } 10 \text { and } 11 \text { inserted between } \\
\text { EcoRI-SalI sites (RA3 coordinates: } 4421-4756)\end{array}$ \\
\hline pOMB1.42 & pBGS18 with virD4 $434-641$; EcoRI-BamHI fragment from pOMB4.42 \\
\hline pOMB1.51 & $\begin{array}{l}\text { pBGS18 with virD4 } 434-641 \mathrm{kfrC} \text {; PCR product amplified on RA3 template with primers } 14 \text { and } 18 \text { inserted as } \\
\text { BglII-SalI fragment between BamHI-SalI sites of pOMB1.42 (RA3 coordinates: 3686-4756) }\end{array}$ \\
\hline pOMB1.74 & $\begin{array}{l}\text { pBGS18 virD4-cfp; BamHI-HindIII fragment from pOMB9.80 with overhangs filled in using Klenow fragment of } \\
\text { PolI inserted within EcoICRI site of pJSB1.5.2 }\end{array}$ \\
\hline pOMB2.0 & $\begin{array}{l}\text { pKAB20 derivative with Ecl136II restriction site inserted between MunI and HindIII sites (annealed } \\
\text { oligonucleotides } 33 \text { and 34) }\end{array}$ \\
\hline pOMB2.0.28 & pUC19 with $k f r C_{244-355-h i s_{6}}$; EcoRI-SmaI fragment from pOMB1.18 inserted in EcoRI-Ecl136II sites of pOMB2.0 \\
\hline pOMB2.49 & $\begin{array}{l}\text { pUC19 with flag-virD4; PCR product amplified on RA3 template with primers } 4 \text { and } 49 \text { inserted between } \\
\text { MunI-HindIII sites of pKAB20 (RA3 coordinates: 18230-16305) }\end{array}$ \\
\hline pOMB2.50 & pUC19 with flag-vird4 $434-641$; EcoRI-SalI fragment from pOMB1.42 inserted between MunI-SalI sites of pKAB20 \\
\hline pOMB2.52 & $\begin{array}{l}\text { pUC19 with flag-virD4 } 434-641 \text { kfrC-his } 6 \text {; EcoRI-SalI fragment from pOMB1.51 inserted between MunI-XhoI sites of } \\
\text { pKAB20 }\end{array}$ \\
\hline pOMB2.74 & $\begin{array}{l}\text { pUC19 virD4-cfp; PCR product amplified on pOMB1.74 template with primers } 1 \text { and } 49 \text { inserted as MunI-SmaI } \\
\text { sites of pOMB2.0 }\end{array}$ \\
\hline pOMB4.0 & pLKB4 derivative with I-SceI restriction site inserted into KpnI site (annealed oligonucleotides 20 and 21) \\
\hline pOMB4.17 & pLKB4 with cyaT18-kfrC $1-249$; EcoRI-SmaI fragment from pOMB1.17 \\
\hline pOMB4.18 & pLKB4 with cyaT18-kfrC $244-355 ;$ EcoRI-SmaI fragment from pOMB1.18 \\
\hline pOMB4.34 & $\begin{array}{l}\text { pLKB4 with cyaT18-tra } G_{R 751} \text {; PCR product amplified on R751 template with primers } 38 \text { and } 39 \text { inserted as } \\
\text { EcoRI-KpnI fragment (R751 coordinates: } 48800-46887)\end{array}$ \\
\hline pOMB4.36 & $\begin{array}{l}\text { pLKB4 with cyaT18-kfr } C_{\mathrm{RK} 2} ; \text { PCR product amplified on RK2 template with primers } 15 \text { and } 16 \text { inserted as } \\
\text { EcoRI-KpnI fragment (RK2 coordinates: } 54424-53079)\end{array}$ \\
\hline pOMB4.38 & $\begin{array}{l}\text { pLKB4 with cyaT18-traG } \mathrm{RK}_{\mathrm{R} 2} \text {; PCR product amplified on RK2 template with primers } 40 \text { and } 41 \text { inserted as } \\
\text { EcoRI-KpnI fragment (RK2 coordinates: } 48495-46588)\end{array}$ \\
\hline pOMB4.42 & $\begin{array}{l}\text { pLKB4 with cyaT18-virD4434-641; PCR product amplified on RA3 template with primers } 47 \text { and } 48 \text { inserted } \\
\text { between EcoRI-BamHI sites (RA3 coordinates: 16931-16305) }\end{array}$ \\
\hline pOMB5.17 & pLKB2 with cyaT25-kfrC $C_{1-249}$; EcoRI-SmaI fragment from pOMB1.17 \\
\hline pOMB5.18 & pLKB2 with cyaT25-kfrC $244-355$; EcoRI-SmaI fragment from pOMB1.18 \\
\hline pOMB5.34 & 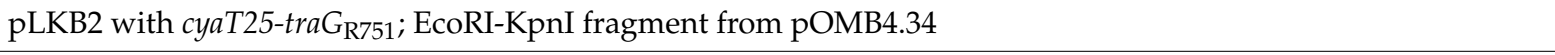 \\
\hline pOMB5.36 & pLKB2 with cyaT25-kfr $C_{\mathrm{RK} 2}$; EcoRI-KpnI fragment from pOMB4.36 \\
\hline pOMB5.38 & pLKB2 with cyaT25-traG $\mathrm{RK} 2_{2}$ EcoRI-KpnI fragment from pOMB4.38 \\
\hline pOMB6.17 & pKGB4 with $k f r C_{1-249}-c y a T 18$; EcoRI-SmaI fragment from pOMB1.17 \\
\hline pOMB6.18 & 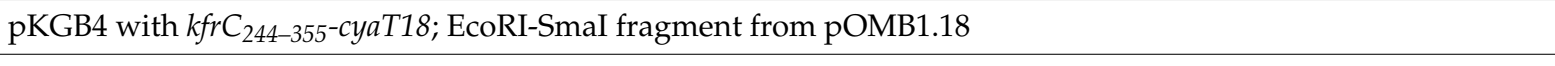 \\
\hline pOMB6.35 & $\begin{array}{l}\text { pKGB4 with traG } G_{R 751}-c y a T 18 ; \text { PCR product amplified on R751 template with primers } 38 \text { and } 43 \text { inserted as } \\
\text { EcoRI-SmaI fragment (R751 coordinates: } 48800-46890)\end{array}$ \\
\hline
\end{tabular}


Table 3. Cont.

\begin{tabular}{|c|c|}
\hline \multicolumn{2}{|c|}{ Plasmids Constructed during This Work } \\
\hline Designation & Relevant Features or Description \\
\hline pOMB6.37 & $\begin{array}{l}\text { pKGB4 with } k f r C_{R K 2}-c y a T 18 \text {; PCR product amplified on RK2 template with primers } 15 \text { and } 17 \text { inserted as } \\
\text { EcoRI-SmaI fragment (RK2 coordinates: } 54424-53082 \text { ) }\end{array}$ \\
\hline pOMB6.39 & $\begin{array}{l}\text { pKGB4 with traG } G_{\mathrm{RK} 2}-c y a T 18 \text {; PCR product amplified on RK2 template with primers } 40 \text { and } 42 \text { inserted as } \\
\text { EcoRI-SmaI fragment (RK2 coordinates: } 48495-46591)\end{array}$ \\
\hline pOMB7.17 & pKGB5 with $k f r C_{1-249}$-cyaT25; EcoRI-SmaI fragment from pOMB1.17 \\
\hline pOMB7.18 & 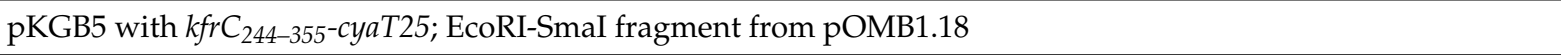 \\
\hline pOMB7.35 & 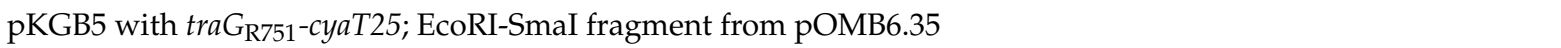 \\
\hline pOMB7.37 & pKGB5 with $k f r C_{\mathrm{RK} 2}$-cyaT25; EcoRI-SmaI fragment from pOMB6.37 \\
\hline pOMB7.39 & pKGB5 with traG $\mathrm{RK}_{2}-\mathrm{cyaT25}$; EcoRI-SmaI fragment from pOMB6.39 \\
\hline pOMB8.28 & pET28mod with $k f r C_{244-355}-h i_{6} ;$ pKAB28 derivative with EcoRI-SalI fragment from pOMB2.0.28 \\
\hline pOMB8.49 & $\begin{array}{l}\text { pET28mod with flag-virD4; MunI-HindIII fragment from pOMB2.49 inserted between EcoRI-HindIII sites of } \\
\text { pKAB28 }\end{array}$ \\
\hline pOMB8.50 & pET28mod with flag-virD4434-641; pKAB28 derivative with EcoRI-SalI fragment from pOMB2.50 \\
\hline pOMB8.52 & pET28mod with flag-virD4 $434-641$ kfrC-his 6 ; pKAB28 derivative with EcoRI-SalI fragment from pOMB2.52 \\
\hline pOMB9.18 & pGBT30 with tacp-kfrC $244-355 ;$ EcoRI-Sall fragment from pOMB1.18 \\
\hline pOMB9.29 & $\begin{array}{l}\text { pGBT30 with tacp-kfrC-his }{ }_{6} \text {; PCR product amplified on the pESB15.90 template with primers } 19 \text { and } 35 \text { inserted } \\
\text { between XbaI-Sall sites of pESB5.88 }\end{array}$ \\
\hline pOMB9.31 & $\begin{array}{l}\text { pGBT30 with tacp-kfrC*; two-stage PCR was used for KfrC site-directed mutagenesis, described in detail in } \\
\text { Metods, PCR final product was inserted between Xbal-Sall sites }\end{array}$ \\
\hline pOMB12.0 & $\begin{array}{l}\text { pOMB12.30 derivative with transcriptional terminator Tpro/Tlyz P1; PCR product amplified on pABB19 as a } \\
\text { template with primers } 50 \text { and } 51 \text { inserted as EcoRI-Sall fragment between EcoRI-XhoI sites }\end{array}$ \\
\hline pOMB12.15 & pESB11 with tacp-kfrC; EcoRI-SalI fragment from pESB5.88 inserted between EcoRI-XhoI sites \\
\hline pOMB12.30 & pBBR1MCS-3 lacI ${ }^{q}$ tacp; pAMB8 derivative with EcoRI-PstI fragment from pGBT30 \\
\hline pOMB12.74 & $\begin{array}{l}\text { pBBR1MCS-2 virD4-cfp; pESB10 derivative with MunI-SmaI fragment from pOMB2.74 inserted between } \\
\text { EcoRI-SmaI sites }\end{array}$ \\
\hline RA3 $\Delta$ incC & $\begin{array}{l}\text { incC gene replaced by } \mathrm{Km}^{\mathrm{r}} \text { cassette amplified on pKD13 template with primers } 52 \text { and } 53 \text { (coordinates of deletion: } \\
6356-7080 \text { ) }\end{array}$ \\
\hline $\mathrm{RA} 3 \Delta n i c$ & $\begin{array}{l}\text { nic gene replaced by } \mathrm{Km}^{\mathrm{r}} \text { cassette amplified on } \mathrm{pKD} 13 \text { template with primers } 54 \text { and } 55 \text { (coordinates of deletion: } \\
\text { 10380-11352) }\end{array}$ \\
\hline RA3 $\Delta v i r D 4$ & $\begin{array}{l}\text { virD4 replaced by } \mathrm{Km}^{\mathrm{r}} \text { cassette amplified on pKD13 template with primers } 56 \text { and } 57 \text { (coordinates of deletion: } \\
\text { 18195-16314) }\end{array}$ \\
\hline $\mathrm{RA} 3 \Delta \operatorname{parS}$ & $\begin{array}{l}\text { parS site replaced by } \mathrm{Km}^{\mathrm{r}} \text { cassette amplified on } \mathrm{pKD} 13 \text { template with primers } 58 \text { and } 59 \text { (coordinates of deletion: } \\
\text { 9707-9722) }\end{array}$ \\
\hline RA3 $\triangle$ oriT & $\begin{array}{l}\text { oriT site replaced by } \mathrm{Km}^{\mathrm{r}} \text { cassette amplified on pKD13 template with primers } 60 \text { and } 61 \text { (coordinates of deletion: } \\
\text { 9747-9756) }\end{array}$ \\
\hline RA3parS $\mathbf{v}$ oriT & $\begin{array}{l}\mathrm{Km}^{\mathrm{r}} \text { cassette amplified on pKD13 template with primers } 59 \text { and } 62 \text { and inserted between parS and oriT sites } \\
\text { (coordinates of insertion: 9722/9723) }\end{array}$ \\
\hline $\mathrm{RA} 3 \Delta k f r A$ & $\begin{array}{l}\text { kfr A replaced by } \mathrm{Km}^{\mathrm{r}} \text { cassette amplified on } \mathrm{pKD} 13 \text { template with primers } 63 \text { and } 64 \text { (coordinates of deletion: } \\
\text { 4892-5935) }\end{array}$ \\
\hline $\mathrm{RA} 3 \Delta k f r C$ & $\begin{array}{l}\text { kfrC replaced by } \mathrm{Km}^{\mathrm{r}} \text { cassette amplified on pKD13 template with primers } 65 \text { and } 66 \text { (coordinates of deletion: } \\
\text { 3695-4738) }\end{array}$ \\
\hline $\mathrm{RA} 3 \Delta(k f r C-A)$ & $\begin{array}{l}k f r C-k f r A \text { replaced by } \mathrm{Km}^{\mathrm{r}} \text { cassette amplified on pKD13 template with primers } 65 \text { and } 64 \text { (coordinates of deletion: } \\
\text { 3695-5935) }\end{array}$ \\
\hline RA3\# & $\operatorname{par}_{\mathrm{P} 1}-\mathrm{Km}^{\mathrm{r}}$ cassette inserted within integron at position 38,663 of RA3 genome \\
\hline
\end{tabular}


Table 4. Oligonucleotides used in this study.

\begin{tabular}{|c|c|c|}
\hline No & Designation & Sequence \\
\hline 1 & CFPSmSaP & gccccggGGTCGACTTACTTGTACAGCTCG \\
\hline 2 & CkorCD & cgacatgtTTATGTTCGGTCATGGTTTC \\
\hline 3 & CkorCG & gcgcatgcCTTAAAGGAGGTGCATAGGT \\
\hline 4 & FLAGVirDR & ccaagcttTTATGCCGCTTCAGCCAAGC \\
\hline 5 & kasmob1 & cggaattcacatgtTTCTCGTTGGAGGGTGATCA \\
\hline 6 & KFRCBSD & tcgacaagcttCCGCT \\
\hline 7 & KFRCBSG & $\underline{\text { CTAGAGCGGaagcttg }}$ \\
\hline 8 & kfrCFL & gcaagctttggaattCATGACCGAACATAAGGCCGA \\
\hline 9 & kfrCIR & cggtcgacttacccgggAGCTCCGCTTTTGCCCATTC \\
\hline 10 & kfrCIIF & cggaattcATGGGCAAAAGCGGAGCTGA \\
\hline 11 & kfrCIIR & cggtcgacTTAcccgggCCGCTCTAGATCGTCTTCAT \\
\hline 12 & kfrCmutF & TGTCGcgGccgCGCTGGCGATGGGCG \\
\hline 13 & kfrCmutR & CCAGCGcggCcgCGACAATCAGATAAGGCTGGTCA \\
\hline 14 & kfrCrbsF & cggaattcagatctaaggagGAAACCATGACCGAACATAA \\
\hline 15 & KfrCRK2N & gcgaattcaTGAGCAGCTACAGCAGAG \\
\hline 16 & KfrCRK2R & gcggtaccTTAGCTGGGCTTGTTTGAC \\
\hline 17 & KfrCRKst & cgccegggGCTGGGCTTGTTTGACAGG \\
\hline 18 & KfrCstop & cggtcgacCCGCTCTAGATCGTCTTCAT \\
\hline 19 & $\mathrm{KfrCXbaF}$ & cgTCTAGAGCGGAAGCTTGCGG \\
\hline 20 & LinkSceF & tagggataacagggtaatgtac \\
\hline 21 & LinkSceR & attaccetgttatccctagtac \\
\hline 22 & mobC1 & cggaattcATGGCAAAGAGCTATCGGATCG \\
\hline 23 & mobC2 & cggtcGACTCGCTTAACTCGGCCTTTCA \\
\hline 24 & mobCT & gcgagctccTTCATCGATCCCCCACTTG \\
\hline 25 & nic1 & cggaattcATGAATAAGGGCTATGACACTCTAGCCGGG \\
\hline 26 & nic2 & cggtcgacTTATCTCTCGTCTTCGTCCC \\
\hline 27 & Nic2k & gcgagctcgTCTCTCGTCTTCGTCCCTCTCTGATTTTGC \\
\hline 28 & OKFRCD2 & tcgacggtaccagcggcttcaCCGCT \\
\hline 29 & OKFRCG2 & $\underline{\text { CTAGAGCGGtgaagccgctggtaccg }}$ \\
\hline 30 & OPETD & GATCGTGCAGC \\
\hline 31 & OPETG & CATGGCTGCAC \\
\hline 32 & pGBT30R & CTCTTCCGCATAAACGCTTC \\
\hline 33 & podst $4 \mathrm{~F}$ & aattggggctcc \\
\hline 34 & podst $4 \mathrm{R}$ & agctggagctcc \\
\hline 35 & T7TERR & gcgtcgacCAAAAAACСССТСAAGACCC \\
\hline 36 & TerpKKKF & cgcggtaccctcgagccegggATCAGAACGCAGAAGCGGTC \\
\hline 37 & TerpKKR & cgcggtaccagtactGGCTTGTAGATATGACGACAG \\
\hline 38 & TraGEcoF & gcgaattcATGAAGATCAAGATGAACAAC \\
\hline 39 & TraGKpnR & gcggtacCTCATATCGTGATGCCCTCCC \\
\hline 40 & TraGRK2F & gcgaattcATGAAGAACCGAAACAACGCC \\
\hline 41 & TraGRK2R & gcggtacCTCATATCGTGATCCCCTCC \\
\hline
\end{tabular}


Table 4. Cont.

\begin{tabular}{|c|c|c|}
\hline No & Designation & Sequence \\
\hline 42 & TraGRKst & cgcccgggTATCGTGATCCССТCСССТTC \\
\hline 43 & TraGSmaR & cgcccgggTATCGTGATGCCCTCCC \\
\hline 44 & virD4Gm & gcggattcATGACCCAGAATTCAAACGGACAC \\
\hline 45 & virD4Kpn & cgggtaCCTTATGCCGCTTCAGCCAAGCCATT \\
\hline 46 & $\operatorname{virD4N}$ & cggagctcCTGCCGCTTCAGCCAAGCCATTAA \\
\hline 47 & VirDfr2F & gcgaattcTTGCGTGAAACATATGGG \\
\hline 48 & VirDfrBR & gcggaTCCTTATGCCGCTTCAGCCAAG \\
\hline 49 & VirDMunF & cgcaattgATGACCCAGAATTCAAACG \\
\hline 50 & TProLyzF & gcgaattctacgtactcgagagatctACATGTGGTACCAACCACC \\
\hline 51 & TProLyzR & gcgtcgacCCATGGATAATAGTTAACGAG \\
\hline 52 & delincF & $\begin{array}{l}\text { CGAGGATGAGGCATATAAACAGGCTAATAAACCAAAGGGT } \\
\text { TGAGCATATGATTCCGGGGATCCGTCGACC }\end{array}$ \\
\hline 53 & delincR & $\begin{array}{l}\text { CCGCTGAGGTCTGCCCCTTTACCACTCATTCAGCCACCCCCATTTTTTCATGTA } \\
\text { GGCTGGAGCTGCTTCG }\end{array}$ \\
\hline 54 & delnicF & $\begin{array}{l}\text { TCGCCGGTTTGCTTCAACGCAACTTAAACAAGTGGGGGATCGATGAATAA } \\
\text { ATTCCGGGGATCCGTCGACC }\end{array}$ \\
\hline 55 & delnicR & $\begin{array}{l}\text { GAACGCTAAATACCTGAAAACAAAAACCGGCCAACAGGCCGGTTTTTTTA } \\
\text { TGTAGGCTGGAGCTGCTTCG }\end{array}$ \\
\hline 56 & delvirF & $\begin{array}{l}\text { TAACGGAGATTTACTATGACCCAGAATTCAAACGGACACAAATGGCGTAAATT } \\
\text { CCGGGGATCCGTCGACC }\end{array}$ \\
\hline 57 & delvirR & $\begin{array}{l}\text { TATGTTTTTTCCTGTGCAATATTTGCCATTTCAATTATTCCTTATGCCGCTGTA } \\
\text { GGCTGGAGCTGCTTCG }\end{array}$ \\
\hline 58 & delparF & $\begin{array}{l}\text { CGACCTGGTGAGCCTGGCCGAAGGCCAAAAGCCACTGCAAAACCGAAAAAATT } \\
\text { CCGGGGATCCGTCGACC }\end{array}$ \\
\hline 59 & delparR & $\begin{array}{l}\text { AGACGCTAGCAAATTGCGAATCCTGCCCTAGTTCTAACCCCCCCATGTTTTGTA } \\
\text { GGCTGGAGCTGCTTCG }\end{array}$ \\
\hline 60 & deloriF & $\begin{array}{l}\text { AACCGAAAAATTTCGTACGTACGAAAAAACATGGGGGGGTTAGAACTAGG } \\
\text { ATTCCGGGGATCCGTCGACC }\end{array}$ \\
\hline 61 & deloriR & $\begin{array}{l}\text { GGGGGACAGGTGCAATTTTAGCACAAGCGGCGGCAGACGCTAGCAAATTG } \\
\text { TGTAGGCTGGAGCTGCTTCG }\end{array}$ \\
\hline 62 & oriparF & $\begin{array}{l}\text { GCCGAAGGCCAAAAGCCACTGCAAAACCGAAAAATTTCGTACGTACGAAA } \\
\text { ATTCCGGGGATCCGTCGACC }\end{array}$ \\
\hline 63 & delkfrAF & $\begin{array}{l}\text { ATGTATTGTATTAAAATACAATACATACAATACAGGGAGCCGAAGCCATG } \\
\text { TGTAGGCTGGAGCTGCTTCG }\end{array}$ \\
\hline 64 & delkfrAR & $\begin{array}{l}\text { CACTTTATCTGTTTACGTCAATAGATAGGGGTTACTCTTTGGTGTCGGCTGC } \\
\text { ATGGGAATTAGCCATGG }\end{array}$ \\
\hline 65 & delkfrCF & $\begin{array}{l}\text { CCTGGCAGGTTTCGGGGCTATATGGGACGCTGACCGGGATTGAAACCATG } \\
\text { TGTAGGCTGGAGCTGCTTCG }\end{array}$ \\
\hline 66 & delkfrCR & $\begin{array}{l}\text { AATGGCCGGGGTCGGTGACAGGGTAGCGGCTTCACCGCTCTAGATCGTCTTC } \\
\text { ATGGGAATTAGCCATGG }\end{array}$ \\
\hline 67 & Kmpar1F & $\begin{array}{l}\text { GGTGCAAAGACGCCGTGGAAGCGTGTGAGGTTGACTCGCGGCTTAGGTAC } \\
\text { ATTCCGGGGATCCGTCGACC }\end{array}$ \\
\hline 68 & Kmpar2R & TGTAGGCTGGAGCTGCTTCG \\
\hline 69 & Kmpar3F & cgaacgagctccagcctacaCTTGCATGCCTGCAGGGTAC \\
\hline 70 & Kmpar4R & $\begin{array}{l}\text { CCCATGTGATCTTCGAGCCGCTGGACTTCATCGCCAAACTCGCTGCGTTG } \\
\text { GGTACCCTGCCGGGGTTCTC }\end{array}$ \\
\hline
\end{tabular}

Start and stop codons are marked in bold, the introduced restriction sites or overhangs are underlined, nucleotides not complementary to the template are shown in small letters, an additional Shine-Dalgarno sequence is underlined, and oligonucleotides used for mutagenesis [30] sequence corresponding to RA3 is in italics. 


\subsubsection{Construction of KfrC Alanine Substitution Mutant}

To introduce mutations into the putative active site of $k f r C$, a two-step PCR was used. The pairs of primers $8 / 13$ and 12/32 (Table 4) were designed to introduce nucleotide substitutions in a particular region accompanied by the introduction of a NotI restriction site to facilitate screening. In the first step, two products were amplified on a pESB5.88 template with primers 8 and 13 or 12 and 32, which after purification served as a template in the second PCR reaction with primers 8 and 32. The final PCR product was inserted between EcoRI-SalI sites of pGBT30 to give pOMB9.31 ( tacp-kfrC*).

4.2.2. Construction of the translational fusions of FLAG with $\operatorname{VirD}_{434-641}$ via N-terminus and $\mathrm{KfrC}$ with $\mathrm{His}_{6}$-tag via C-terminus

The $k f r C$ gene without a stop codon was amplified with primers 14/18 and cloned downstream of virD4 $4_{434-641}$ in pOMB1.42. The EcoRI-Sall fragment with both genes was re-cloned into pKAB20 and digested using MunI and XhoI restriction enzymes to create translational fusions of FLAG-VirD4 ${ }_{434-641}$ and $\mathrm{KfrC}-\mathrm{His}_{6}$, respectively. Finally, the EcoRISall fragment carrying flag-virD $4_{434-641} \mathrm{kfrC}-\mathrm{his}_{6}$ was re-cloned into pKAB28 (pET28mod derivative) to obtain pOMB8.52.

\subsubsection{Construction of RA3\# Derivative with $\operatorname{par}_{\mathrm{P} 1}-\mathrm{Km}^{\mathrm{r}}$ Cassette}

$\mathrm{Km}^{\mathrm{r}}$ cassette amplified on a pKD13 template with primers 67 and 68 and par $S_{\mathrm{P} 1}$ prophage amplified on a pOMB3.104 template with primers 69 and 70 were used as a template in the second PCR reaction with primers 67 and 70. The final PCR product was inserted within integron at position 38,663 of the RA3 genome with the use of the Datsenko and Wanner method [30].

\subsection{Bacterial Transformation and Conjugation}

Bacterial transformation was done using the standard methods [50]. Electroporation was carried out using 2-mm gap cuvettes at $25 \mu \mathrm{F}, 200 \Omega, 2.5 \mathrm{kV}$ in a Bio-Rad Gene Pulser.

The E. coli DH5 $\alpha$ transformants with RA3 variants or the helper strain E. coli S17-1 harboring pESB11 or pOMB12.15 (tacp-kfrC) were used as the donors in the conjugations with the chosen Rifr ${ }^{r}$ strains of $A$. tumefaciens, P. aminovorans, A. veronii, C. necator, or P. putida as described previously $[18,26]$. Briefly, aliquots of $100 \mu \mathrm{L}$ of stationary phase cultures of the donor and recipient strains, rinsed previously with $\mathrm{L}$ broth, were mixed on an $\mathrm{L}$ agar plate and incubated overnight at $28^{\circ} \mathrm{C}$. Bacteria were washed off the plate and serial dilutions were plated on an appropriate solid medium selective for transconjugants. The frequency of the conjugative transfer of RA3 or its derivatives between E. coli strains or P. putida strains was analyzed using a modification of this method. Suspensions of donor and recipient cells were mixed on the sterile nitrocellulose filters and incubated on $\mathrm{L}$ agar plate at $37^{\circ} \mathrm{C}$ or $28^{\circ} \mathrm{C}$. Filters were immersed into $0.2 \mathrm{~mL}$ of $\mathrm{L}$ broth, vortexed, and serial dilutions plated on L-agar with antibiotics selective for transconjugants. After $24-48 \mathrm{~h}$ of incubation at $28^{\circ} \mathrm{C}$ or $37^{\circ} \mathrm{C}$, obtained colonies were counted. Suspension of the donor cells was treated in the same manner but incubated separately on the filter to serve as a reference. Conjugation frequency was expressed as the number of transconjugant colonies per donor colonies formed. The reported values are the average of at least three different experiments.

\subsection{Bacterial Adenylate Cyclase Two-Hybrid (BACTH) System}

Possible interactions between proteins were analyzed in vivo using the BACTH system [34] as described previously [26]. Genes encoding proteins of interest were cloned into the BACTH vectors to create translational fusions with CyaAT18 (pKGB4, pLKB4 plasmids) or CyaAT25 (pKGB5, pLKB2) fragments via N- or C-terminus, respectively. Pairs of the compatible plasmids were cotransformed into E. coli BTH101 cyaA and transformants were selected on L agar supplemented with kanamycin, penicillin, and $0.15 \mathrm{mM} \mathrm{IPTG.}$ Bacteria were incubated for approximately $48 \mathrm{~h}$ and randomly chosen transformants were 
re-streaked on the selective MacConkey medium with $1 \%$ maltose as a carbon source. Reconstitution of the CyaA activity due to the interactions between analyzed proteins led to the activation of sugar catabolism operons in E. coli, e.g., mal and lac, manifested by forming purple colonies on maltose containing solid medium and an increase of $\beta$-galactosidase activity in the extracts from the liquid cultures. The $\beta$-galactosidase activity was assayed using the standard method [61]. One unit of $\beta$-galactosidase is defined as the amount of enzyme needed to convert $1 \mu \mathrm{mol}$ of $o$-nitrophenyl- $\beta$-D-galactopyranoside (ONPG) to $o$-nitrophenol and D-galactose in 1 min under standard conditions.

\subsection{Genome-Wide Library Construction of E. coli, A. veronii, and RA3 Plasmid Using BACTH System}

For genomic DNA extraction of E. coli DH5 $\alpha$ and A. veronii, the modified method of Chen and Kuo was used [62]. For plasmid RA3, the large-scale isolation Plasmid Giga Kit (QIAGEN) was used and the additional step of electroelution of the plasmid DNA from the agarose pad into the dialysis bags was applied [63] that separated the plasmid DNA from genomic DNA contamination. Obtained DNA was fragmented and cloned into the pOMB4.0 vector as described in detail in the supplemental material. The quality of the obtained genomic library was evaluated by determination of its size, the percentage of the genome coverage, and the percentage of the plasmids that have an insert. The probability of having a particular fragment inserted in the right orientation and in frame with the cyaT18 fragment was calculated using the formula below [64].

$$
p=1-(1-\mathrm{i} / 6 \mathrm{G})^{\mathrm{N}}
$$

$\mathrm{i}$ - the mean insert size [bp]

$\mathrm{G}$ - the genome size [bp]

$\mathrm{N}$-the number of clones obtained in the library

\subsection{High-Throughput Screening of Interaction Partners for a Bait Protein}

Genomic libraries constructed in the pUT18C vector derivative (pOMB4.0) were used for a high-throughput search of the protein-protein interactions. Between 2-60 ng of the library was transformed into $50 \mu \mathrm{L}$ of the E. coli BTH101 strain harboring the vector pOMB5.15 (T25-KfrC) or pOMB7.16.1 (KfrC-T25). The transformation mixture was washed twice with $1 \mathrm{~mL}$ of sterile water and plated on a minimal medium with selective antibiotics, thiamine, maltose as a carbon source, X-gal as an indicator, and $0.1 \mathrm{mM}$ IPTG. After 3-5 days of incubation in $28{ }^{\circ} \mathrm{C}$, blue colonies were picked up and re-streaked on the same selective medium and grown under the same conditions. Directly from the colonies remaining blue after replating, plasmid DNA was isolated using the phenol:chloroform method [50] and obtained DNA was used to transform the E. coli BTH101 strain containing the bait vector and plated on selective MacConkey plates containing maltose as the sole carbon source and $0.1 \mathrm{mM}$ IPTG. After $48 \mathrm{~h}$ at $28{ }^{\circ} \mathrm{C}$, plasmid DNA was isolated from the clones, which appeared red. The restriction pattern analysis step allowed us to eliminate the false-positive results that arose from the genetic rearrangements within vectors and caused a reversion of $\mathrm{Cya}^{-}$to $\mathrm{Cya}^{+}$phenotype. After confirmation of a restriction pattern, the inserts in pOMB4.0 were sequenced and analyzed further.

Chosen isolated plasmid DNAs were used to transform the E. coli DH5 $\alpha$ strain and transformants were plated on the penicillin plates and verified to be $\mathrm{Km}^{\mathrm{S}}$ (cured of the bait plasmid). From a single clone $\left(\mathrm{Ap}^{\mathrm{R}}, \mathrm{Km}^{\mathrm{S}}\right.$ ), the pUT18C derivative encoding prey protein was isolated and retested for interaction with the bait by the transformation the E. coli BTH101 with the bait vector or the empty pKT25 vector. Positively verified interactions resulted in PCR cloning of the DNA fragments encoding the full-length prey proteins into the BACTH system and further analysis. 


\subsection{Overexpression and Purification of $\mathrm{His}_{6}$-tagged Proteins by Affinity Chromatography}

For overproduction, E. coli BL21(DE3) carrying pESB15.90, pET28mod derivative, encoding the $\mathrm{C}$-terminally $\mathrm{His}_{6}$-tagged $\mathrm{KfrC}$ was used. The purification procedure was performed as described previously via affinity chromatography [18] with the use of a washing buffer ( $50 \mathrm{mM} \mathrm{NaPi} \mathrm{pH}$ 8.0, $300 \mathrm{mM} \mathrm{NaCl}, 10 \mathrm{mM}$ imidazole, $10 \%$ glycerol). The protein purification was monitored by SDS-PAGE using the PhastSystem (Pharmacia). Protein concentration was determined using the Bradford method [65].

For the SEC-MALS and circular dichroism methods, protein purification was performed in two steps, via affinity (Ni-NTA column, Qiagen) and gel-filtration (Superdex200 16/60 column, GE Healthcare) chromatography using an automated FPLC AKTAexpress GE system. Standard purification buffers were used with the difference that the sonication and washing buffers contained $10 \mathrm{mM} \beta$-mercaptoethanol.

\subsection{Determination of Protein Oligomeric States by Size-Exclusion Chromatography Coupled to} Multiangle Light Scattering (SEC-MALS)

His $_{6}$-tagged $\mathrm{KfrC}$ at a concentration of $1 \mathrm{mg} \mathrm{mL}^{-1}$ purified with an automated FPLC AKTAexpress GE system was loaded on a Superdex200 10/300 GL column (GE Healthcare) equilibrated with an SEC buffer $(50 \mathrm{mM} \mathrm{NaPi}$ buffer $\mathrm{pH} 7.5,0.15 \mathrm{M} \mathrm{NaCl})$. The protein was eluted from the column at a flow rate of $0.5 \mathrm{~mL} \mathrm{~min}^{-1}$. Each fraction was automatically analyzed by multiangle light scattering (DAWN HELEOS II, Wyatt Technology), UV $280 / 254 \mathrm{~nm}$ (1260 Infinity LC, Agilent Technologies), and differential refractometry (Optilab T-rEX, Wyatt Technology) detectors. Data processing and molecular mass calculations were performed with the Astra program (Wyatt Technology).

\subsection{Crosslinking with Glutaraldehyde}

The ability of a $\mathrm{His}_{6}$-tagged $\mathrm{KfrC}$ or its truncated form, $\mathrm{KfrC}_{244-355}$ to form dimers or multimers was examined using glutaraldehyde as described previously [66] with a slight modification. Instead of the purified proteins, $1-2 \mu \mathrm{L}$ of cell extract containing overproduced protein was used in the crosslinking reactions. Reaction products were separated by SDS-PAGE and analyzed by Western blotting using anti-His 6 tag antibodies. The cell extract of a strain containing an empty vector was used as a control.

\subsection{Western Blot Analysis}

The proteins separated by SDS-PAGE [50] and electrotransferred from the polyacrylamide gel to a nitrocellulose membrane (Amersham ${ }^{\mathrm{TM}}$ Protran ${ }^{\circledR}$ Cytiva) using the wet transfer Bio-Rad block were subjected to immunodetection as described in the supplemental material.

\subsection{Determination of the Protein Secondary Structure by Circular Dichroism (CD) Spectroscopy}

CD measurements were carried out at 200-270 nm using a Jasco J-815 CD spectrometer with a step size of $1 \mathrm{~nm}$ and bandwidth of $2 \mathrm{~nm}$ in $1 \mathrm{~mm}$ path length quartz cuvettes. The protein sample purified with an automated FPLC AKTAexpress GE system at a concentration of $1.5 \mu \mathrm{M}$ was dissolved in a $50 \mathrm{mM} \mathrm{NaPi}$ buffer ( $\mathrm{pH}$ 7.5) containing $0.15 \mathrm{M}$ $\mathrm{NaCl}$ with the addition of $30 \%$ TFE (2,2,2-trifluoroethanol) or without TFE. Measurements were performed at a temperature of $25^{\circ} \mathrm{C}, 37^{\circ} \mathrm{C}$, and $42{ }^{\circ} \mathrm{C}$, and with the addition of TFE only at a temperature of $25^{\circ} \mathrm{C}$. The partition of secondary structures was estimated with the BestSel program [33]. After subtracting appropriate blanks, the mean residue ellipticity [deg $\mathrm{cm}^{2} \mathrm{dmol}^{-1}$ ] was calculated according to the formula below [67].

$$
[\theta]_{\mathrm{MR}}=100 \theta /(\mathrm{clN})
$$

$\theta$-ellipticity [deg]

c-the concentration of protein $[\mathrm{M}]$

1 -the path length [cm]

$\mathrm{N}$-number of amino acids 


\subsection{Construction of RA3 Mutants Using Site-Directed Mutagenesis Based on $\lambda$ Red-Mediated Recombination}

Defined deletions or insertions in the RA3 plasmid were prepared with the use of the standard method [30], which allows an exchange of a genetic region by a DNA fragment conferring resistance to kanamycin with the assistance of $\lambda$ Red recombinase.

DNA fragments were amplified using Phanta polymerase and primers homologous, partly (20 nt) to the vector pKD13 carrying a Km resistance cassette, and partly (50 nt) to the targeted sequence. After the DNA product digestion using the DpnI enzyme to eliminate the remaining methylated template DNA and purification, it was used for electrotransformation of electrocompetent E. coli BW25113 cells carrying pKD46 and RA3 plasmid prepared using a standard method with the difference that $1 \mathrm{mM} \mathrm{L}$-arabinose was used to induce expression of $\lambda$ Red recombinase. After electroporation, cell suspension was plated on selective $\mathrm{L}$ agar plates and incubated overnight at $37^{\circ} \mathrm{C}$, at which temperature transformant cells were cured of thermosensitive pKD46. Subsequently, the $\mathrm{Km}^{\mathrm{r}} \mathrm{Ap}^{\mathrm{s}}$ transformants were analyzed via PCR to confirm the deletion of the desired region or proper DNA fragment insertion. For the positively verified clones, the region of deletion or insertion was amplified, and the mutant construction was confirmed via PCR product sequencing.

\subsection{Co-Immunoprecipitation}

Coimmunoprecipitation of $\mathrm{KfrC}$ with $\mathrm{VirD} 4_{434-641}$ was done using a modified method previously described [68]. The E. coli BL21(DE3) strain was transformed with pOMB8.52 (T7p-flag-virD4 $\left.4_{434-641} \mathrm{kfrC}-\mathrm{his}_{6}\right)$ or pOMB8.50 (T7p-flag-virD4434-641), which served as a control. Overnight cultures of the transformants were diluted 1:50 into a fresh medium and after one hour of growth protein overproduction was induced with $0.5 \mathrm{mM}$ IPTG for another four hours. The cultures were incubated with formaldehyde $(1 \% v / v)$ at room temperature with gentle agitation for $30 \mathrm{~min}$. After sonication of the pelleted cells, the immunoprecipitation procedure proceeded with anti-His antibodies (Invitrogen) as described in the supplemental material. Western blot analysis of the initial cell extracts and the Co-IP samples with the use of anti-FLAG antibodies (Invitrogen), diluted 1:2000, was carried out after protein separation by SDS-PAGE and transfer onto a nitrocellulose membrane.

\subsection{Determination of Growth Rate of Strains Overproducing Proteins}

Overnight cultures of the analyzed strains were diluted 1:100 in L broth with IPTG $(0.5 \mathrm{mM})$ or without IPTG. Cultures were grown under selective conditions at $28^{\circ} \mathrm{C}$ or $37^{\circ} \mathrm{C}$ with agitation for $8 \mathrm{~h}$ (flasks) or $24 \mathrm{~h}$ (VarioskanTM Lux Microplate reader) and $\mathrm{OD}_{600}$ measurements were performed every hour or every half hour, respectively. Growth curves were prepared based on the three cultures for each strain. The strain containing the empty vector was used as a control. Generation time, when appropriate, was estimated on the basis of colony forming units (c.f.u.) at subsequent time points of culture growth.

\subsection{Observations of the Nucleoids after DAPI Staining}

To observe nucleoid localization in the cells, an overnight culture of an appropriate strain was diluted in L broth supplemented without and with $0.5 \mathrm{mM}$ IPTG when needed and grown under selective conditions with agitation to the $\mathrm{OD}_{600} 0.6-0.8$. Subsequently, $200 \mu \mathrm{L}$ of the culture were transferred to the new sterile microfuge tube and immediately mixed with the equal volume of the fixation buffer $(2.68 \%(w / v)$ paraformaldehyde, $0.005 \%$ $(w / v)$ glutaraldehyde in PBS (pH 7.4; $137 \mathrm{mM} \mathrm{NaCl}, 2.7 \mathrm{mM} \mathrm{KCl}, 10 \mathrm{mM} \mathrm{Na} 2 \mathrm{HPO}_{4}$, $\left.1.8 \mathrm{mM} \mathrm{K}_{2} \mathrm{HPO}_{4}\right)$ ). After $15 \mathrm{~min}$ of incubation at room temperature and the next $15 \mathrm{~min}$ incubation on ice, cells were washed twice with PBS and the pellet was re-suspended in the $200 \mu \mathrm{L}$ of PBS. A few $\mu \mathrm{L}$ of the fixed cell suspension were placed on a microscopic slide covered with $0.01 \%(w / v)$ poly-l-lysine (Sigma). After 10 min of incubation, notattached cells were removed via triple PBS washing. Microscopic slides were allowed to 
dry and DAPI/Vectashield mixed in proportion 1:4 was added to cover the cells (DAPI (4', 6-diamidino-2-phenylindole) $1 \mu \mathrm{g} / \mathrm{mL}$ in PBS with Vectashield (Vector Laboratories Inc.)).

\subsection{Plasmid Stability Assays}

The stability of RA3 or its derivatives were tested as described previously [18]. Briefly, stationary-phase cultures grown under antibiotic selection were diluted $10^{5}$-fold into the fresh medium (without antibiotic) and cultivated for approximately 20 generations. In parallel, diluted cultures were plated on L agar to get approximately 100-200 colonies then 100 colonies were re-streaked onto $\mathrm{L}$ agar with the selective antibiotic to estimate the number of bacteria retaining the plasmid. Plasmid retention was expressed as the percentage of antibiotic-resistant colonies. Culture refreshing and plating procedures were repeated every 20 generations for up to 60 generations. For each strain, stability experiments were performed in triplicate starting from three separate colonies.

\subsection{Fluorescence Microscopy}

The strains containing appropriate expression vector derivatives encoding translational fusions of analyzed proteins with CFP or YFP under tacp $\left(\operatorname{lacl}^{q}\right)$ were used for microscopic observations. The overnight culture was diluted 1:100 in L broth supplemented with $0.01 \mathrm{mM}$ IPTG when needed and grown under selective conditions. When $\mathrm{OD}_{600}$ reached 0.5-0.8, the cells were washed twice with PBS and the pellet was re-suspended in the PBS and a few $\mu \mathrm{L}$ of the cell suspension were applied on a microscopic slide. Bacterial cells were visualized at $100 \times$ magnification using a fluorescent microscope Carl Zeiss Axio Imager.M2 and AxioCamMR5 camera. Collected pictures were processed and analyzed with the program AxioVision Rel.4.8.2 (Carl Zeiss).

Supplementary Materials: The following are available online at https://www.mdpi.com/article/ 10.3390/ijms22094880/s1, Figure S1: Determination of the A. veronii genomic DNA fragments mean size and insertion efficiency into PUT18C derivative vector-colony PCR products visualized on an agarose gel, Figure S2: Validation of the KfrC-T25 interactions found in the (A) E. coli DH5 $\alpha$, (B) A. veronii and (C) RA3 genome-fragment libraries screening, Figure S3: Alignment of VirD4 $4_{\mathrm{RA} 3}$ (ABD64846) and $\mathrm{TraG}_{\mathrm{RK} 2}$ (Q00184).

Author Contributions: Conceptualization, M.A. and G.J.-B.; formal analysis, M.M.; funding acquisition, M.A. and G.J.-B.; investigation, M.M., E.L. and J.G.; project administration, G.J.-B.; supervision, G.J.-B.; validation, M.M., E.L., J.G. and G.J.-B.; visualization, M.M., E.L. and G.J.-B.; writing-original draft, G.J.-B.; writing—review \& editing, M.M., E.L., M.A. and G.J.-B. All authors have read and agreed to the published version of the manuscript.

Funding: This research was funded by the consortium grant from the National Science Center, Poland, grant number 2015/17/B/NZ2/01160 (granted to M.A.).

Institutional Review Board Statement: Not applicable.

Informed Consent Statement: Not applicable.

Data Availability Statement: All obtained data is included in the manuscript and Supplement.

Acknowledgments: We gratefully acknowledge financial and technical support from the Institute of Biochemistry and Biophysics, PAS and partly from the Faculty of Chemistry of Warsaw University of Technology. We thank Kamil Kobylecki for help with MALS-SEC and Radoslaw Kotuniak for help in $\mathrm{CD}$ analysis. The equipment used in the $\mathrm{CD}$ analysis was sponsored partly by the Centre for Preclinical Research and Technology (CePT), a project cosponsored by the European Regional Development Fund and Innovative Economy, the National Cohesion Strategy of Poland.

Conflicts of Interest: The authors declare no conflict of interest. 


\section{References}

1. De Boer, P.; Crossley, R.; Rothfield, L. The Essential Bacterial Cell-Division Protein FtsZ Is a GTPase. Nature 1992, $359,254-256$. [CrossRef]

2. Wagstaff, J.; Löwe, J. Prokaryotic Cytoskeletons: Protein Filaments Organizing Small Cells. Nat. Rev. Microbiol. 2018, 16, 187-201. [CrossRef] [PubMed]

3. Celler, K.; Koning, R.I.; Koster, A.J.; Wezel, G.P. van Multidimensional View of the Bacterial Cytoskeleton. J. Bacteriol. 2013, 195, 1627-1636. [CrossRef] [PubMed]

4. Amos, L.A.; Löwe, J. Overview of the Diverse Roles of Bacterial and Archaeal Cytoskeletons. Subcell. Biochem. 2017, 84, 1-26. [CrossRef]

5. Kelemen, G.H. Intermediate Filaments Supporting Cell Shape and Growth in Bacteria. In Prokaryotic Cytoskeletons: Filamentous Protein Polymers Active in the Cytoplasm of Bacterial and Archaeal Cells; Löwe, J., Amos, L.A., Eds.; Subcellular Biochemistry; Springer International Publishing: Cham, Switzerland, 2017; pp. 161-211. ISBN 978-3-319-53047-5.

6. Pollard, T.D.; Goldman, R.D. Overview of the Cytoskeleton from an Evolutionary Perspective. Cold Spring Harb. Perspect. Biol. 2018, 10. [CrossRef] [PubMed]

7. Gerdes, K.; Howard, M.; Szardenings, F. Pushing and Pulling in Prokaryotic DNA Segregation. Cell 2010, 141, 927-942. [CrossRef]

8. Michie, K.A.; Löwe, J. Dynamic Filaments of the Bacterial Cytoskeleton. Annu. Rev. Biochem. 2006, 75, 467-492. [CrossRef]

9. Lin, L.; Thanbichler, M. Nucleotide-Independent Cytoskeletal Scaffolds in Bacteria. Cytoskeleton 2013, 70, 409-423. [CrossRef]

10. Shih, Y.L.; Rothfield, L. The Bacterial Cytoskeleton. Microbiol. Mol. Biol. Rev. 2006, 70, 729-754. [CrossRef]

11. Chaikeeratisak, V.; Khanna, K.; Nguyen, K.T.; Sugie, J.; Egan, M.E.; Erb, M.L.; Vavilina, A.; Nonejuie, P.; Nieweglowska, E.; Pogliano, K.; et al. Viral Capsid Trafficking along Treadmilling Tubulin Filaments in Bacteria. Cell 2019, 177, 1771-1780.e12. [CrossRef]

12. Kraemer, J.A.; Erb, M.L.; Waddling, C.A.; Montabana, E.A.; Zehr, E.A.; Wang, H.; Nguyen, K.; Pham, D.S.L.; Agard, D.A.; Pogliano, J. A Phage Tubulin Assembles Dynamic Filaments by a Novel Mechanism to Center Viral DNA within the Host Cell. Cell 2012, 149, 1488-1499. [CrossRef]

13. Adamczyk, M.; Dolowy, P.; Jonczyk, M.; Thomas, C.M.; Jagura-Burdzy, G. The KfrA Gene Is the First in a Tricistronic Operon Required for Survival of IncP-1 Plasmid R751. Microbiol. Read. Engl. 2006, 152, 1621-1637. [CrossRef]

14. Fernández-López, R.; Garcillán-Barcia, M.P.; Revilla, C.; Lázaro, M.; Vielva, L.; de la Cruz, F. Dynamics of the IncW Genetic Backbone Imply General Trends in Conjugative Plasmid Evolution. FEMS Microbiol. Rev. 2006, 30, 942-966. [CrossRef] [PubMed]

15. Iiyama, K.; Mon, H.; Mori, K.; Mitsudome, T.; Lee, J.M.; Kusakabe, T.; Tashiro, K.; Asano, S.; Yasunaga-Aoki, C. Characterization of KfrA Proteins Encoded by a Plasmid of Paenibacillus Popilliae ATCC 14706T. Meta Gene 2015, 4, 29-44. [CrossRef] [PubMed]

16. Jagura-Burdzy, G.; Thomas, C.M. KfrA Gene of Broad Host Range Plasmid RK2 Encodes a Novel DNA-Binding Protein. J. Mol. Biol. 1992, 225, 651-660. [CrossRef]

17. Kulinska, A.; Godziszewska, J.; Wojciechowska, A.; Ludwiczak, M.; Jagura-Burdzy, G. Global Transcriptional Regulation of Backbone Genes in Broad-Host-Range Plasmid RA3 from the IncU Group Involves Segregation Protein KorB (ParB Family). Appl. Environ. Microbiol. 2016, 82, 2320-2335. [CrossRef] [PubMed]

18. Lewicka, E.; Mitura, M.; Steczkiewicz, K.; Kieracinska, J.; Skrzynska, K.; Adamczyk, M.; Jagura-Burdzy, G. Unique Properties of the Alpha-Helical DNA-Binding Protein KfrA Encoded by the IncU Incompatibility Group Plasmid RA3 and Its Host-Dependent Role in Plasmid Maintenance. Appl. Environ. Microbiol. 2021, 87. [CrossRef]

19. Li, X.; Top, E.M.; Wang, Y.; Brown, C.J.; Yao, F.; Yang, S.; Jiang, Y.; Li, H. The Broad-Host-Range Plasmid PSFA231 Isolated from Petroleum-Contaminated Sediment Represents a New Member of the PromA Plasmid Family. Front. Microbiol. $2014,5,777$. [CrossRef]

20. Van der Auwera, G.A.; Król, J.E.; Suzuki, H.; Foster, B.; Van Houdt, R.; Brown, C.J.; Mergeay, M.; Top, E.M. Plasmids Captured in C. Metallidurans CH34: Defining the PromA Family of Broad-Host-Range Plasmids. Antonie Leeuwenhoek 2009, 96, 193-204. [CrossRef]

21. Dolowy, P. The Regulatory Network of RA3 Plasmid from IncU Group. The Role of Kfr Proteins in Stable Maintenance. Ph.D. Thesis, Institute of Biochemistry and Biophysics, PAS, Warsaw, Poland, 2007.

22. Kulinska, A.; Czeredys, M.; Hayes, F.; Jagura-Burdzy, G. Genomic and Functional Characterization of the Modular Broad-HostRange RA3 Plasmid, the Archetype of the IncU Group. Appl. Environ. Microbiol. 2008, 74, 4119-4132. [CrossRef]

23. Godziszewska, J.; Kulinska, A.; Jagura-Burdzy, G. MobC of Conjugative RA3 Plasmid from IncU Group Autoregulates the Expression of Bicistronic MobC-Nic Operon and Stimulates Conjugative Transfer. BMC Microbiol. 2014. [CrossRef]

24. Kulinska, A.; Cao, Y.; Macioszek, M.; Hayes, F.; Jagura-Burdzy, G. The Centromere Site of the Segregation Cassette of Broad-HostRange Plasmid RA3 Is Located at the Border of the Maintenance and Conjugative Transfer Modules. Appl. Environ. Microbiol. 2011, 77, 2414-2427. [CrossRef] [PubMed]

25. Ludwiczak, M.; Dolowy, P.; Markowska, A.; Szarlak, J.; Kulinska, A.; Jagura-Burdzy, G. Global Transcriptional Regulator KorC Coordinates Expression of Three Backbone Modules of the Broad-Host-Range RA3 Plasmid from IncU Incompatibility Group. Plasmid 2013, 70, 131-145. [CrossRef]

26. Lewicka, E.; Dolowy, P.; Godziszewska, J.; Litwin, E.; Ludwiczak, M.; Jagura-Burdzy, G. Transcriptional Organization of Stability Module of Broad-Host-Range RA3 Plasmid from IncU Group. Appl. Environ. Microbiol. 2020. [CrossRef] 
27. Godziszewska, J.; Moncalián, G.; Cabezas, M.; Bartosik, A.A.; de la Cruz, F.; Jagura-Burdzy, G. Concerted Action of NIC Relaxase and Auxiliary Protein MobC in RA3 Plasmid Conjugation. Mol. Microbiol. 2016, 101, 439-456. [CrossRef] [PubMed]

28. Aoki, T.; Egusa, S.; Kimura, T.; Watanabe, T. Detection of R Factors in Naturally Occurring Aeromonas Salmonicida Strains. Appl. Microbiol. 1971, 22, 716-717. [CrossRef] [PubMed]

29. Adamczyk, M.; Lewicka, E.; Szatkowska, R.; Nieznanska, H.; Ludwiczak, J.; Jasiński, M.; Dunin-Horkawicz, S.; Sitkiewicz, E.; Swiderska, B.; Goch, G.; et al. Revealing Biophysical Properties of KfrA-Type Proteins as a Novel Class of Cytoskeletal, Coiled-Coil Plasmid-Encoded Proteins. BMC Microbiol. 2021, 21, 32. [CrossRef]

30. Datsenko, K.A.; Wanner, B.L. One-Step Inactivation of Chromosomal Genes in Escherichia Coli K-12 Using PCR Products. Proc. Natl. Acad. Sci. USA 2000, 97, 6640-6645. [CrossRef]

31. Roccatano, D.; Colombo, G.; Fioroni, M.; Mark, A.E. Mechanism by Which 2,2,2-Trifluoroethanol/Water Mixtures Stabilize Secondary-Structure Formation in Peptides: A Molecular Dynamics Study. Proc. Natl. Acad. Sci. USA 2002, 99, 12179-12184. [CrossRef]

32. Roy, A.; Kucukural, A.; Zhang, Y. I-TASSER: A Unified Platform for Automated Protein Structure and Function Prediction. Nat. Protoc. 2010, 5, 725-738. [CrossRef]

33. Micsonai, A.; Wien, F.; Bulyáki, É.; Kun, J.; Moussong, É.; Lee, Y.-H.; Goto, Y.; Réfrégiers, M.; Kardos, J. BeStSel: A Web Server for Accurate Protein Secondary Structure Prediction and Fold Recognition from the Circular Dichroism Spectra. Nucleic Acids Res. 2018, 46, W315-W322. [CrossRef]

34. Karimova, G.; Pidoux, J.; Ullmann, A.; Ladant, D. A Bacterial Two-Hybrid System Based on a Reconstituted Signal Transduction Pathway. Proc. Natl. Acad. Sci. USA 1998, 95, 5752-5756. [CrossRef] [PubMed]

35. Piotrowska, M.; Popowska, M. Insight into the Mobilome of Aeromonas Strains. Front. Microbiol. 2015, 6. [CrossRef] [PubMed]

36. Atmakuri, K.; Cascales, E.; Christie, P.J. Energetic Components VirD4, VirB11 and VirB4 Mediate Early DNA Transfer Reactions Required for Bacterial Type IV Secretion. Mol. Microbiol. 2004, 54. [CrossRef]

37. Pansegrau, W.; Lanka, E.; Barth, P.T.; Figurski, D.H.; Guiney, D.G.; Haas, D.; Helinski, D.R.; Schwab, H.; Stanisich, V.A.; Thomas, C.M. Complete Nucleotide Sequence of Birmingham IncP $\propto$ Plasmids: Compilation and Comparative Analysis. J. Mol. Biol. 1994, 239, 623-663. [CrossRef] [PubMed]

38. Thorsted, P.B.; Macartney, D.P.; Akhtar, P.; Haines, A.S.; Ali, N.; Davidson, P.; Stafford, T.; Pocklington, M.J.; Pansegrau, W.; Wilkins, B.M.; et al. Complete Sequence of the IncP $\beta$ Plasmid R751: Implications for Evolution and Organisation of the IncP Backbone11Edited by J. Karn. J. Mol. Biol. 1998, 282, 969-990. [CrossRef]

39. Li, Y.G.; Christie, P.J. The Agrobacterium VirB/VirD4 T4SS: Mechanism and Architecture Defined Through In Vivo Mutagenesis and Chimeric Systems. Curr. Top. Microbiol. Immunol. 2018, 418, 233-260. [CrossRef]

40. Lu, J.; Frost, L.S. Mutations in the C-Terminal Region of TraM Provide Evidence for in Vivo TraM-TraD Interactions during F-Plasmid Conjugation. J. Bacteriol. 2005, 187, 4767-4773. [CrossRef] [PubMed]

41. Moncalián, G.; de la Cruz, F. DNA Binding Properties of Protein TrwA, a Possible Structural Variant of the Arc Repressor Superfamily. Biochim. Biophys. Acta BBA Proteins Proteom. 2004, 1701, 15-23. [CrossRef]

42. Alvarez-Martinez, C.E.; Christie, P.J. Biological Diversity of Prokaryotic Type IV Secretion Systems. Microbiol. Mol. Biol. Rev. MMBR 2009, 73, 775-808. [CrossRef] [PubMed]

43. Kwak, M.-J.; Kim, J.D.; Kim, H.; Kim, C.; Bowman, J.W.; Kim, S.; Joo, K.; Lee, J.; Jin, K.S.; Kim, Y.-G.; et al. Architecture of the Type IV Coupling Protein Complex of Legionella Pneumophila. Nat. Microbiol. 2017, 2, 17114. [CrossRef]

44. Guynet, C.; Cuevas, A.; Moncalián, G.; de la Cruz, F. The Stb Operon Balances the Requirements for Vegetative Stability and Conjugative Transfer of Plasmid R388. PLoS Genet. 2011, 7. [CrossRef] [PubMed]

45. Gruber, C.J.; Lang, S.; Rajendra, V.K.H.; Nuk, M.; Raffl, S.; Schildbach, J.F.; Zechner, E.L. Conjugative DNA Transfer Is Enhanced by Plasmid R1 Partitioning Proteins. Front. Mol. Biosci. 2016, 3. [CrossRef]

46. Simon, R.; Priefer, U.; Pühler, A.; Preifer, U. A Broad Host Range Mobilization System for In Vivo Genetic Engineering: Transposon Mutagenesis in Gram Negative Bacteria. Nature Biotechnol. 1983. [CrossRef]

47. Koekman, B.P.; Hooykaas, P.J.J.; Schilperoort, R.A. A Functional Map of the Replicator Region of the Octopine Ti Plasmid. Plasmid 1982, 7, 119-132. [CrossRef]

48. Czarnecki, J.; Dziewit, L.; Puzyna, M.; Prochwicz, E.; Tudek, A.; Wibberg, D.; Schlüter, A.; Pühler, A.; Bartosik, D. LifestyleDetermining Extrachromosomal Replicon PAMV1 and Its Contribution to the Carbon Metabolism of the Methylotrophic Bacterium Paracoccus Aminovorans JCM 7685. Environ. Microbiol. 2017, 19, 4536-4550. [CrossRef]

49. Kahn, M.; Kolter, R.; Thomas, C.; Figurski, D.; Meyer, R.; Remaut, E.; Helinski, D.R. [17] Plasmid cloning vehicles derived from plasmids ColE1, F, R6K, and RK2. In Methods in Enzymology; Recombinant DNA; Academic Press: Cambridge, MA, USA, 1979; Volume 68, pp. 268-280. [CrossRef]

50. Sambrook, J.; Russell, D.W. Molecular Cloning: A Laboratory Manual; Cold Spring Harbor Laboratory Press: Cold Spring Harbor, NY, USA, 2001.

51. Bartosik, A.A.; Markowska, A.; Szarlak, J.; Kulińska, A.; Jagura-Burdzy, G. Novel Broad-Host-Range Vehicles for Cloning and Shuffling of Gene Cassettes. J. Microbiol. Methods 2012, 88, 53-62. [CrossRef]

52. Kawalek, A.; Glabski, K.; Bartosik, A.A.; Fogtman, A.; Jagura-Burdzy, G. Increased ParB Level Affects Expression of Stress Response, Adaptation and Virulence Operons and Potentiates Repression of Promoters Adjacent to the High Affinity Binding Sites ParS3 and ParS4 in Pseudomonas Aeruginosa. PLoS ONE 2017, 12, e0181726. [CrossRef] [PubMed] 
53. Kovach, M.E.; Phillips, R.W.; Elzer, P.H.; Roop, R.M.; Peterson, K.M. PBBR1MCS: A Broad-Host-Range Cloning Vector. BioTechniques 1994, 16, 800-802.

54. Kovach, M.E.; Elzer, P.H.; Hill, D.S.; Robertson, G.T.; Farris, M.A.; Roop, R.M.; Peterson, K.M. Four New Derivatives of the Broad-Host-Range Cloning Vector PBBR1MCS, Carrying Different Antibiotic-Resistance Cassettes. Gene 1995, 166, 175-176. [CrossRef]

55. Spratt, B.G.; Hedge, P.J.; te Heesen, S.; Edelman, A.; Broome-Smith, J.K. Kanamycin-Resistant Vectors That Are Analogues of Plasmids PUC8, PUC9, PEMBL8 and PEMBL9. Gene 1986, 41, 337-342. [CrossRef]

56. Lukaszewicz, M.; Kostelidou, K.; Bartosik, A.A.; Cooke, G.D.; Thomas, C.M.; Jagura-Burdzy, G. Functional Dissection of the ParB Homologue (KorB) from IncP-1 Plasmid RK2. Nucleic Acids Res. 2002, 30, 1046-1055. [CrossRef] [PubMed]

57. Jagura-Burdzy, G.; Ibbotson, J.P.; Thomas, C.M. The KorF Region of Broad-Host-Range Plasmid RK2 Encodes Two Polypeptides with Transcriptional Repressor Activity. J. Bacteriol. 1991, 173, 826-833. [CrossRef]

58. Kawalek, A.; Modrzejewska, M.; Zieniuk, B.; Bartosik, A.A.; Jagura-Burdzy, G. Interaction of ArmZ with the DNA-Binding Domain of MexZ Induces Expression of MexXY Multidrug Efflux Pump Genes and Antimicrobial Resistance in Pseudomonas Aeruginosa. Antimicrob. Agents Chemother. 2019, 63. [CrossRef] [PubMed]

59. Mierzejewska, J.; Bartosik, A.A.; Macioszek, M.; Płochocka, D.; Thomas, C.M.; Jagura-Burdzy, G. Identification of C-Terminal Hydrophobic Residues Important for Dimerization and All Known Functions of ParB of Pseudomonas Aeruginosa. Microbiol. Read. Engl. 2012, 158, 1183-1195. [CrossRef] [PubMed]

60. Yanisch-Perron, C.; Vieira, J.; Messing, J. Improved M13 Phage Cloning Vectors and Host Strains: Nucleotide Sequences of the M13mp18 and PUC19 Vectors. Gene 1985, 33, 103-119. [CrossRef]

61. Miller, J.H. Experiments in Molecular Genetics; Cold Spring Harbor Laboratory: Cold Spring Harbor, NY, USA, 1972; ISBN 978-0-87969-106-6.

62. Chen, W.P.; Kuo, T.T. A Simple and Rapid Method for the Preparation of Gram-Negative Bacterial Genomic DNA. Nucleic Acids Res. 1993, 21, 2260. [CrossRef] [PubMed]

63. McKenney, K.; Shimatake, H.; Court, D.; Schmeissner, U.; Brady, C.; Rosenberg, M. A System to Study Promoter and Terminator Signals Recognized by Escherichia Coli RNA Polymerase. Gene Amplif. Anal. 1981, 2, 383-415. [PubMed]

64. Clarke, L.; Carbon, J. A Colony Bank Containing Synthetic Col El Hybrid Plasmids Representative of the Entire E. Coli Genome. Cell 1976, 9, 91-99. [CrossRef]

65. Bradford, M.M. A Rapid and Sensitive Method for the Quantitation of Microgram Quantities of Protein Utilizing the Principle of Protein-Dye Binding. Anal. Biochem. 1976, 72, 248-254. [CrossRef]

66. Jagura-Burdzy, G.; Thomas, C.M. Purification of KorA Protein from Broad Host Range Plasmid RK2: Definition of a Hierarchy of KorA Operators. J. Mol. Biol. 1995, 253, 39-50. [CrossRef] [PubMed]

67. Greenfield, N.J. Using Circular Dichroism Spectra to Estimate Protein Secondary Structure. Nat. Protoc. 2006, 1, 2876-2890. [CrossRef] [PubMed]

68. Bartosik, A.A.; Glabski, K.; Jecz, P.; Lasocki, K.; Mikosa, M.; Plochocka, D.; Thomas, C.M.; Jagura-Burdzy, G. Dissection of the Region of Pseudomonas Aeruginosa ParA That Is Important for Dimerization and Interactions with Its Partner ParB. Microbiology 2014, 160, 2406-2420. [CrossRef] [PubMed] 